\title{
Antibiotic therapy against Pseudomonas aeruginosa in cystic fibrosis: a European consensus
}

\author{
G. Döring*, S.P. Conway**, H.G.M. Heijerman", M.E. Hodson ${ }^{\# \#}$, N. Høiby ${ }^{\S}$, A. Smyth ${ }^{+}$, D.J. Touw ${ }^{++}$, \\ for the Consensus Committee
}

Antibiotic therapy against Pseudomonas aeruginosa in cystic fibrosis: a European consensus. G. Döring, S.P. Conway, H.G.M. Heijerman, M.E. Hodson, N. Høiby, A. Smyth, D.J. Touw, for the Consensus Committee. (C)ERS Journals Ltd 2000.

ABSTRACT: Cystic fibrosis $(\mathrm{CF})$ is the most common lethal hereditary disorder with autosomal recessive heredity in caucasians. The majority of $\mathrm{CF}$ patients suffer from chronic respiratory infection with the opportunistic bacterial pathogen Pseudomonas aeruginosa. No consensus among clinicians has been reached so far concerning antibiotic treatment against $P$. aeruginosa in $C F$ patients.

Consensus answers to 24 important questions in this context, based on current evidence, are presented, given by a panel of 34 European experts. Questions addressed and answered are: The diagnosis of $P$. aeruginosa lung colonization in CF; The impact of $P$. aeruginosa on the clinical state of $C F$ patients; The assessment of $P$. aeruginosa susceptibility against antibiotics and the importance of these results for the clinician; The use of monotherapy versus combination therapy; The development of microbial resistance; The achievement of optimal airway concentrations; The effects of subinhibitory concentrations of antibiotics on $P$. aeruginosa; Statements on the pharmacokinetics of antibiotics in CF patients; Recommendations for doses and dosing intervals and length of treatment regimens; and Toxic side effects due to repeated antibiotic therapy was addressed.

The expert panel answered further questions on the use of fluoroquinolones in children with $C F$, on the administration of nebulized antibiotics and whether prevention of $P$. aeruginosa lung colonization is possible in CF using antibiotic therapy.

Problems of antibiotic therapy at home and in the hospital were addressed, a consensus statement on regular maintenance treatment, or treatment on demand, was given and different routes of administration of antibiotics were recommended for different clinical situations.

Finally, the factors which determine the choice of the antibiotic, the dosage, and the duration of the treatment in cystic fibrosis patients were addressed and the design of future antibiotic studies in the context of Pseudomonas aeruginosa lung infection in cystic fibrosis patients were recommended.

Eur Respir J 2000; 16: 749-767.
*Hygiene-Institut, University of Tübingen, Tübingen, Germany, **St Jame's \& Seacroft Hospital, Regional Adult Cystic Fibrosis Unit, Leeds, UK, "Ziekenhuis Leyenburg, Den Haag, the Netherlands, "Royal Brompton Hospital, The Cardiothorcic Institute, London, UK, "Laboratory Centre, Klinisk Mikrobiologisk afdeling, Copenhagen, Denmark, ${ }^{+}$Dept of Paediatrics, Nottingham City Hospital, Nottingham, UK, ${ }^{+}+$Academic Hospital Vrije Universiteit, Dept of Pharmacy, Amsterdam, the Netherlands.

Correspondence: G. Döring, Dept of General and Environmental Hygiene, Hygiene-Institute, University of Tübingen, Wilhelmstrasse 31, D-72074 Tübingen, Germany. Fax: 497071293011

Keywords: Antibiotic therapy, consensus, cystic fibrosis, Pseudomonas aeruginosa

Received: May 22000

Accepted after revision June 202000

This document is the result of an European Consensus Conference which took place in Artimino, Tuscany, Italy, in November 1999 involving 34 experts on antibiotic therapy against Pseudomonas aeruginosa in cystic fibrosis patients, organized by the European Cystic Fibrosis Society, and sponsored by PathoGenesis (major sponsor), Astra-Zeneca, Aventis, Bayer, GlaxoWellcome, Lilly and Pharmax. The purpose of the conference was to develop a consensus document on antibiotic treatment against $P$. aeruginosa in cystic fibrosis patients based on current evidence.
Cystic fibrosis (CF) is a worldwide disease occurring in virtually all ethnic groups. In Caucasians it is the most common lethal hereditary disorder with autosomal recessive heredity [1]. About 1 in 25 are heterozygous carriers, while the incidence of clinical disease is $\sim 1$ in 2,500 live births [1], with a prevalence of $\sim 50,000$ recognized patients worldwide. Disease is caused by mutations in a single gene of chromosome 7 , which encodes the CF transmembrane conductance regulator (CFTR) [2]. The CFTR protein is a membrane bound cyclic adenosine monophosphate (cAMP)-regulated chloride channel which is thought to regulate other cell membrane ion channels [3]. More than 800 different mutations have been identified so far, however, a deletion of phenyla-

For editorial comments see page 583. lanine in the amino acid position 508 is present in $\sim 66 \%$ of all CF patients worldwide. CFTR mutations affect epithelial ion and water transport mainly in cells in the respiratory, gastrointestinal, hepatobiliary and reproductive tracts. In CF airways diminished chloride and water secretion leads to viscous secretions and impaired mucociliary clearance [3].

A hallmark of $C F$ is chronic respiratory infection, which may start very early in the life of these patients [4-6]. Since the early description of CF, pulmonary infection has been recognized as having the greatest role in morbidity and mortality leading to premature death in $90 \%$ of patients [5]. Pulmonary infections in CF are unique because of the underlying basic defect, the restriction of infection to the pulmonary tract and the chronic nature of infection with progressive tissue damage due to chronic inflammation. 
Pseudomonas aeruginosa, a Gram-negative bacterium, which also causes infections in patients with severe burns, cancer, and paraplegia [7], is the most frequently described opportunistic pathogen in CF patients. It is ubiquitous and is found in many water reservoirs in the inanimate and human environment [8]. Water reservoirs polluted by humans or animals, such as with sewage, are the most frequent environmental sources of $P$. aeruginosa. $P$. aeruginosa is seldom and transiently isolated from healthy humans.

$P$. aeruginosa is the most frequent pathogen isolated from $\mathrm{CF}$ sputum or bronchoalveolar lavage samples of CF patients of all age groups [5, 9, 10]. Many children with $\mathrm{CF}$ develop respiratory tract infection early in their lives. Epidemiological data from the Cystic Fibrosis Foundation, USA, including $20,000 \mathrm{CF}$-patients, revealed that $29.8 \%$ in the age groups of $2-5$ yrs and $81.3 \%$ in the age group of 26-30 yrs are infected with $P$. aeruginosa [5]. Similar values are obtained in European countries [10]. An overall incidence of $P$. aeruginosa infections in CF is estimated at $8 \%$.

Epidemiological studies using different typing methods for $P$. aeruginosa suggest that transmission of $P$. aeruginosa to CF patients may occur by a direct patient-topatient contact. In addition, transmission of $P$. aeruginosa to $\mathrm{CF}$ patients may occur via contaminated environmental reservoirs [8].

CF centres have separated CF patients with and without $P$. aeruginosa infection in order to limit cross-infection [11]. In addition, hygienic measures to decontaminate environmental reservoirs of $P$. aeruginosa including nebulizers [12] and other medical equipment, sinks, toilets and dental tubings, have been recommended. Additionally hand disinfection for CF patients and hospital personnel has been stressed [8]. Vaccination against $P$. aeruginosa in CF patients has been studied [13]. Whereas in most trials vaccines do not appear to prevent lung infection in $\mathrm{CF}$ patients $[14,15]$, administration of a polysaccharide-exotoxin A conjugate vaccine may have some clinical efficacy [16]. Currently, a multi-centre trial with a bivalent $P$. aeruginosa flagella vaccine including $>500 \mathrm{CF}$ patients in Europe is in progress [17].

\section{Pathogenesis of the chronic Pseudomonas aeruginosa lung infection in cystic fibrosis patients}

The exact route(s) of entry of the bacteria into the lower airways of CF patients is not known. It is generally believed that the pathogen reaches the lower airways through mouth or nose passage. The reason for the peculiar interaction of $P$. aeruginos $a$ with the CF lung epithelium is unclear at present, although several hypotheses have been offered. Binding of $P$. aeruginosa to components of the mucus layer on top of the cilia and failure to clear thickened mucus from airway surfaces is likely [18]. P. aeruginosa colonization of CF airways triggers an inflammatory response with concomitant release of a number of cytokines, such as interleukin-8, which is chemotactic to polymorphonuclear leukocytes (neutrophils).

Whereas mostly nonmucoid $P$. aeruginosa is cultured in vitro from oropharyngeal $\mathrm{CF}$ specimens soon after onset of infection, mucoid $P$. aeruginosa, characterized by the formation of exopolysaccharide (alginate)-coated microcolonies (biofilm mode of growth), is nearly uniformly present in chronic infection [9]. Mucoid $P$. aeruginosa is more resistant against phagocytosis [19] and may also restrict the penetration of antibiotics. Mucoid $P$. aeruginosa is often nonmotile and this phenotype persists in a nutrient rich, mostly anaerobic environment.

The pathogenesis of chronic $P$. aeruginosa lung infection in CF has been classified as a type III hypersensitivity reaction, characterized by the production of specific antibodies against a large number of bacterial antigens, immune complexes and large numbers of neutrophils [9, 20]. The decaying neutrophils form large areas of pus around the persisting bacteria, which may lead to total obstruction of CF airways. The release of high extracellular concentrations of lysosomal serine proteinases far exceeds the endogenous antiproteinase capacity. Progressive proteolytic impairment of multiple defense pathways in addition to endobronchial tissue destruction are thought to be responsible for the significantly reduced life expectancy in CF patients [20].

\section{Diagnosis of Pseudomonas aeruginosa lung infection and its clinical course in cystic fibrosis patients}

P. aeruginosa lung infection in CF patients is generally diagnosed by taking sputum, hypopharyngeal or endolaryngeal suctions or deep throat culture, preferably after lung physiotherapy or alternatively after hypertonic (3\%) saline inhalation. P. aeruginosa grows well on standard laboratory media such as 5\% sheep blood agar or chocolate agar $[21,22]$. Selective media, such as cetrimide agar, facilitate the isolation of $P$. aeruginosa from other bacterial species. Plates are incubated at $35^{\circ} \mathrm{C}$ in a $5 \% \mathrm{CO}_{2}$ atmosphere for 24 h. P. aeruginosa is easily identified by characteristic colony morphology and standard microbiological methods $[21,22]$. P. aeruginosa isolates may differ concerning their morphotypes including mucoid, smooth, rough, dwarf and small colony varieties, and morphological varieties from a single patient may differ in antibiotic susceptibility patterns [22, 23]. However, different morphotypes mostly belong to a single genotype. The time required to identify $P$. aeruginosa and assess its antibiotic susceptibility pattern from a sputum culture is $\sim 3-4$ days. However, small colony variants may only grow after $48 \mathrm{~h}$ agar cultivation and thus may be overlooked in routine diagnostics [24]. Gram-stained smears of patient materials are used to detect neutrophils and squamous epithelial cells besides micro-organisms and will indicate the adequacy of the sputum sample.

In non-expectorating patients oropharyngeal cultures yielding $P$. aeruginosa are highly predictive [25]. However, false-negative results from throat cultures may occur making additional diagnostic tools necessary. Sensitive serological tests for $P$. aeruginosa antigens such as crossed immunoelectrophoresis, radioimmunoassay (RIA) and enzyme-linked immunosorbent assay (ELISA) have been especially useful in this context [26]. The presence of $P$. aeruginosa in throat culture and negative $P$. aeruginosa antibody titres may help to distinguish between early colonization and chronic infection. P. aeruginosa colonization/infection may start in the first year of life of 
a CF patient $[3,4,6,10,27]$ and it is believed that early therapeutic intervention will delay progressive lung damage caused by $P$. aeruginosa or even prevent or delay the onset of chronic infection.

It has been demonstrated that clinical progression of lung disease with deterioration of forced expiratory volume in one second (FEV1) occurred despite the disappearance of $P$. aeruginosa from sputum specimens, suggesting that lung disease can also progress with other bacteria [28]. Additionally, epidemiological data show that infection with $P$. aeruginosa is confounded with the degree of pulmonary impairment which already exists [29] and that $P$. aeruginosa, although associated with some decrease in FEV1, does not cause sudden deterioration in CF patients [30]. Apparently, some patients can tolerate P. aeruginosa colonization for years without decline of lung function. They are frequently, though not necessarily, characterized by harbouring nonmucoid $P$. aeruginosa strains, absent or low antibody titers to the organisms and absent or little sputum production.

However, in the majority of $\mathrm{CF}$ patients producing sputum and carrying mucoid $P$. aeruginosa, the infection causes an immediate and more rapid reduction of lung function than in CF patients without $P$. aeruginosa infection [9]. This leads to the hypothesis that uncontrolled progression of infection will result in progressively severe lung damage, respiratory failure and death. Indirect evidence for the latter hypothesis stems from the fact that sputum volumes increase significantly after onset of $P$. aeruginosa infection. Higher sputum volumes are correlated with a higher degree of inflammation, higher neutrophil numbers and released serine proteinases and hence higher degree of lung obstruction and destruction. Not all clinicians, however, agree to this description of the pathophysiology of the $P$. aeruginosa lung infection, as pulmonary exacerbations from other causes may lead to similar clinical changes.

The use of antibiotics for $P$. aeruginosa lung infection in $\mathrm{CF}$ patients has been questioned by only a few investigators. When $P$. aeruginosa-infected CF patients were treated for acute exacerbations with antibiotics, the shortterm clinical outcome was comparable to the placebo treated group [31]. Based on unchanged sputum colony counts during or after intravenous antibiotic therapy, it was concluded that antipseudomonal therapy in CF patients requires more critical bacteriological and clinical evaluation [32].

However, several other studies investigating various antibiotics for $P$. aeruginosa in CF patients found a positive effect on clinical condition, pulmonary function, $P$. aeruginosa colony counts in sputum, inflammatory parameters, quality of life and nutritional status of the patients. Epidemiological data showed that lung function is the best predictor of survival [29] and antibiotic therapy has lead to improvement in lung function in many studies [33, 34]. The observation that the degree of improvement in lung function correlated with the degree of reduction of $P$. aeruginosa density in sputum specimens [34] suggests that antibiotic therapy is directly responsible for lung function improvement. For long-term effect, however, the influence of anti- $P$. aeruginosa treatment is difficult to evaluate since no controlled studies have been performed and such long-term studies would be difficult to carry out without well defined therapeutic strategies and due to complexity of the management of the patient and a limited patient population.

$\mathrm{CF}$ is a multi-faceted disease and many different treatment strategies have been implemented during the last $40 \mathrm{yrs}$. Therefore, it is difficult to prove that antibiotic treatment alone is responsible for the dramatic positive change in survival rates of CF patients in some countries. Besides antibiotics, improved mucolytic therapy, airway physiotherapy, improved nutritional strategies including the use of pancreatic enzyme preparations have contributed to the increased life expectancy in CF patients. The median survival age of CF patients in the USA increased from 14 yrs in 1969 to 31.3 yrs in 1996 [5]. In Denmark, the probability of surviving $40 \mathrm{yrs}$ for a diagnosed CF patient was $83.3 \%$ in 1995 [35]. This improved survival has been correlated with an early anti-P. aeruginosa treatment regimen in Denmark [35].

\section{Antibiotic resistance of Pseudomonas aeruginosa in cystic fibrosis}

Traditionally, many decisions to treat $P$. aeruginosa lung infections in CF patients are empirical and are based in part on patient's age, severity of disease and past experience rather than on $P$. aeruginosa susceptibility patterns against antibiotics. Bacterial susceptibility (or resistance) patterns against antibiotics are assessed in vitro using the relatively simple disk diffusion method, which is regarded to give qualitative results according to established break-points, or the quantitative dilution methods (agar dilution, microdilution broth, macrodilution broth). By using an automated broth microdilution method, synergistic effects of combinations of different antibiotics can be demonstrated which may help to guide antibiotic therapy regimes in $\mathrm{CF}$ patients [36].

For sputa containing susceptible isolates, testing the mixed culture may provide adequate susceptibility data with significant laboratory time and cost savings [23]. However, for sputa with resistant strains, the traditional method of testing isolated morphotypes may be more appropriate [23].

Several problems arise when $P$. aeruginosa susceptibility patterns against antibiotics are used for clinical treatment in CF patients: 1) multiple morphotypes with different antibiotic susceptibilities are often isolated from a single sputum sample $[22,23]$; 2) the conventional definition of antibiotic resistance, which is based on the comparison of serum drug levels and minimal inhibitory concentrations (MIC) in vitro does not apply to CF lung infections when treated with inhaled antibiotics [37]; 3) The biofilm mode of growth of $P$. aeruginosa requires $100-1,000$ times the concentration of a certain antibiotic to be effective compared to its nonmucoid variant which is normally tested [38]. Nevertheless, for several antibiotics tested, nonmucoid isolates were more resistant than mucoid isolates [39].

Whether CF patients should be treated over prolonged periods of time with antibiotics to which $P$. aeruginosa is resistant, according to definitions used in Europe or North America, remains unclear at present. Actual data on $P$. aeruginosa susceptibility patterns against antibiotics are missing in Europe but may be retrieved from CF databases. 
When antibiotic therapy had been started before susceptibility patterns had been available, the therapy has to be adjusted accordingly.

Chronic $P$. aeruginosa infections in $\mathrm{CF}$ necessitates many antibiotic therapy courses which carry the risk that resistance towards a given drug increases more or less rapidly. Consequently, $P$. aeruginosa often display higher resistance to older drugs which have been used more frequently compared to newly developed drugs [40-42].

Also trials with nebulized antibiotics in CF patients, resulted in the emergence of resistant $P$. aeruginosa isolates in the sputum during and after treatment with great variations [33, 43-47]. For instance, a study of inhaled tobramycin showed that the percentage of patients harbouring $P$. aeruginosa strains with a tobramycin MIC $>8$ $\mu \mathrm{g} \cdot \mathrm{mL}^{-1}$ increased from $29-73 \%$ after 3 months of continuous use of $600 \mathrm{mg}$ three times daily [47]. Therefore, studies using an intermittent regimen of inhaled tobramycin have been conducted $[33,45,46]$. With this regime, the percentage of patients harbouring $P$. aeruginosa with a tobramycin MIC $>16 \mu \mathrm{g} \cdot \mathrm{mL}^{-1}$ increased from $13-$ $25 \%$ only. In a subsequent open tobramycin study over 18 months using a daily dose of $600 \mathrm{mg}$, the increase of the MIC of tobramycin had no negative effect on lung function of the patients [48].

The emergence of resistant micro-organisms has been reported to be transient and reverted to susceptible over time, when antibiotic selective pressure is removed, a phenomenon which was called "adaptive resistance" [49]. The mechanism which leads to adaptive resistance may be based on a slower growth rate of resistant colonial forms of $P$. aeruginosa compared to susceptible ones. Generally, nonmucoid $P$. aeruginosa is more resistant to antibiotics than mucoid $P$. aeruginosa [39]. Consequently, susceptible organisms will overgrow resistant forms after the end of the antibiotic course. Frequent changing from one antipseudomonal antibiotic to another may be an option to prevent antibiotic resistant $P$. aeruginosa.

The emergence of resistant micro-organisms does not necessarily lead to a poor response to repeated treatment $[41,44,47,50,51]$. Nevertheless, the emergence of multiresistant $P$. aeruginosa strains from $\mathrm{CF}$ patients is well known. Current epidemiological data on the prevalence of antibiotic resistant $P$. aeruginosa infecting CF patients in European countries other than Italy [52] and Denmark [53] are missing.

Depending on the mode of action of a given antibiotic, more or less rapid development of resistance occurs [54] especially with monotherapy, when the drug has to be given for prolonged periods of time. Indeed, a high development of ceftazidime-resistant strains of $P$. aeruginosa was noted in a small population of CF patients who received ceftazidime monotherapy over a 5 -yr period $[55$, 56]. This would imply that antibiotic monotherapy is inferior to combination therapy with $P$. aeruginosaspecific antibiotics displaying different mode of actions. For example, $\beta$-lactam antibiotics such as the penicillins and cephalosporins, interfere with bacterial cell wall biosynthesis, novobiocin and the quinolones inhibit deoxyribonucleic (DNA) synthesis by acting on topoisomerases and rifampin inhibits DNA-directed ribonucleic (RNA) synthesis. In contrast, aminoglycosides as well as chloramphenicol, erythromycin, clindamycin and the tetracyclines inhibit protein synthesis by binding to bacterial ribosomal subunits or inhibiting ribosomal enzymes [57].

However, when intravenously administered ticarcillin and tobramycin was compared to ceftazidime, development of resistance to multiple antibiotics was significantly lower with ceftazidime alone compared to the ticarcillin/ tobramycin group [58]. Other studies revealed that development of resistant strains is not prevented by the use of a combination of tobramycin and $\beta$-lactam antibiotics [59, 60]. In addition, emergence of resistant micro-organisms during aerosolization of colistin alone seems to be rare, although published evidence is lacking. Nevertheless, combination therapy is widely used in CF patients.

Selection of intrinsically resistant pathogens after antibiotic therapy in CF patients may occur, yet no evidence of increased selection for intrinsically tobramycin-resistant bacterial pathogens, including Burkholdia cepacia, Stenotrophomonas, and Alcaligenes xylosoxidans was reported when intermittent inhaled tobramycin therapy was compared with standard antimicrobial therapy [37]. However, there was increased isolation of Candida albicans and Aspergillus spp. in the treatment group compared with the placebo group [37]. Such a development was not observed in a previous study using aerosolized colistin in CF [43]. The clinical significance of these findings is unclear, since long-term data on $\mathrm{CF}$ patients who have received inhaled tobramycin for several years are missing.

\section{Penetration of antibiotics into respiratory secretions and pharmacokinetics of antibiotics in cystic fibrosis patients}

Antibiotics are believed to enter the bronchial secretions from the blood by simple passive diffusion along a concentration gradient [61]. Aminoglycosides diffuse poorly across lipid membranes and into bronchial secretions and their distribution is mainly restricted to the extracellular fluid. Although tobramycin has the highest penetration into bronchial secretions of aminoglycosides studied [62, 63], relatively high dosages are needed when the drug is given parenterally. Therefore, it is generally recommended to administer aminoglycosides by inhalation for maintenance therapy. Intravenous aminoglycoside doses have to be adjusted according to the serum levels of the patient because of toxicity and efficacy of the drugs and therefore may change from patient to patient. Doses can be adjusted based on a mathematical model [64], which, however, is not available in many centres. A practical approach is to determine serum trough and peak levels of aminoglycosides.

Data on airway concentrations of aminoglycosides [47, 65] as well as on other antibiotics [66, 67] are sparse and depend on the mode of delivery [67]. Once daily dosing of amikacin and tobramycin achieves higher airway concentrations than multiple daily dosing [68]. The general applicability of once daily dosing is, however, pending. When the drugs are used via the inhaled route during acute exacerbations clinical experience suggests low efficacy and therefore intravenous use is preferred [69]. Further studies which compare intravenous and inhaled administration of antibiotics during acute exacerbations are necessary. 
Table 1. - Recommended dosages for antibacterial agents in the management of $P$. aeruginosa lung infections in cystic fibrosis patients

\begin{tabular}{|c|c|c|c|c|}
\hline Antibiotics & $\begin{array}{c}\text { Route of } \\
\text { administration }\end{array}$ & $\begin{array}{c}\text { Dose } \\
\mathrm{mg} \cdot \mathrm{kg}^{-1} \cdot \mathrm{day}^{-1}\end{array}$ & $\begin{array}{l}\text { Administrations } \\
\text { per day } n\end{array}$ & $\begin{array}{l}\text { Maximum daily } \\
\text { dose } \mathrm{g}\end{array}$ \\
\hline Amikacin* & i.v. & 30 & 2 & - \\
\hline \multirow[t]{2}{*}{ Aztreonam } & i.v. & 150 & 4 & 8 \\
\hline & i.v. & 100 & continuously & 8 \\
\hline Cefepime & i.v. & $100-150$ & $2-3$ & 6 \\
\hline Ceftazidime & i.v. & $150-250$ & $3-4$ & 12 \\
\hline Ceftazidime & i.v. & $100-150$ & continuously & 12 \\
\hline Ciprofloxacin & p.o. & 30 & $2-3$ & $1.5-2.25$ \\
\hline Colistin & Inhaled & $80-160^{\#}$ & $1-2$ & $0.320^{\#}$ \\
\hline Sulphomethate & i.v. & $160^{\#}$ & 3 & 0.48 \\
\hline Imipenem/cilastatin & i.v. & $50-100$ & $3-4$ & 4 \\
\hline \multirow[t]{2}{*}{ Meropenem } & i.v. & $60-120$ & 3 & 6 \\
\hline & i.v. & 60 & continuously & 3 \\
\hline Netilmicin* & i.v. & 10 & 2 & - \\
\hline Ticarcillin & i.v. & $500-750$ & 4 & 30 \\
\hline \multirow[t]{2}{*}{ Tobramycin* } & i.v. & 10 & 2 & - \\
\hline & Inhaled & $150-300^{\#}$ & $1-2$ & 0.6 \\
\hline
\end{tabular}

*: dose based on measurements of serum concentrations; ${ }^{\#}$ : absolute dose (dependent on age and situation). These recommendations may not be the approved dosing recommendations by regulatory authorities in different countries.

Penicillin and cephalosporins do not enter bronchial secretions well and bronchial secretions and sputum concentrations usually range $3-15 \%$ of plasma levels [70]. Based on a minimum inhibition concentration inhibiting $90 \%$ of tested strains (MIC90) for ceftazime and $P$. aeruginosa of $8 \mu \mathrm{g} \cdot \mathrm{mL}^{-1}$, the amount of drug to be administered parenterally every $6 \mathrm{~h}$ would be $300 \mathrm{mg} \cdot \mathrm{kg}^{-1}$ [70]. However, when administered continuously, a much lower dose can be used. Penicillins and cephalosporins are generally administered intravenously. For classes of antibiotics other than aminoglycosides given intravenously, monitoring of serum levels is not required because of their wide therapeutic index and recommended doses as given in table 1 should be used.

Administration of ciprofloxacin orally has resulted in sputum concentrations ranging from $46-90 \%$ of those obtained in serum $[64,71]$. flouroquinolones are given either intravenously or orally. The latter route is preferred because of good absorption. The intravenous route is much more expensive and less convenient for the patient. Colistin given by inhalation is widely used for maintenance therapy and for eradication of early colonization/ infection with $P$. aeruginosa. Due to its chemical nature, a product which upon hydrolysis releases the active drug, a cycle polypeptide, analysis of colistan airway concentrations are impossible to preform and therefore the optimum levels are not known. Efficiency has been shown at doses ranging from 1 million units twice daily [43] to 2 million units three times daily [72]. Colistin has been used with efficiency by the parenteral route in patients with multiresistant $P$. aeruginosa infection $[73,74]$.

In addition to penetration into bronchial secretions, plug formation may present another problem for antibiotic action. CF plugs are mainly composed of negatively charged glycoproteins and DNA. Other macromolecules, and positively charged aminoglycosides. such as tobramycin, may be bound to these compounds [75-78]. Because of these reasons appropriate airway clearance should be performed before inhalation of aminoglycosides or colistin. No data on flouroquinolones binding to charged macromolecules are available. Ceftazidime binding to sputum is negligible [78]. A further obstacle for antibiotics to reach the $P$. aeruginosa outer cell membrane in $\mathrm{CF}$ plugs is the mucoid exopolysaccgaride (alginate) matrix [79]. In vitro models have been developed to evaluate the penetration of ceftazidime into plugs [64]. Taken together, bactericidal concentrations of antibiotics in $\mathrm{CF}$ plugs are difficult to reach and it has to be assumed that often only subinhibitory concentrations can be obtained. The same is true for poorly ventilated areas.

Subinhibitory concentrations of antibiotics may positively affect the clinical condition and the lung function of CF patients [80-84]. For instance, ciprofloxicin [81] and gentamicin [83] inhibit exotoxin production of $P$. aeruginosa, which may decrease inflammation in CF due to decreased immune complex formation. Tobramycin and gentamicin inactivate oxygen radicals by binding to amino groups [80] and ticarcillin and ceftazidime may protect $\alpha_{1}$-antitrypsin from oxygen radical damage [80]. Whether such modifications will lead to inactivation of antibiotics is unknown. However, subinhibitory concentrations of antibiotics may change the mutation rate of $P$. aeruginosa facilitating the development of resistant variants (adaptive mutation). They may also trigger adaptive resistance [49].

The pharmacokinetics of antibiotics in CF patients have been extensively studied $[64,76,85-93]$. CF patients often reveal different pharmacokinetics particularly for aminoglycosides and $\beta$-lactam-antibiotics when compared with normal individuals. The volume of distribution per $\mathrm{kg}$ body weight is often increased and the elimination half-life decreased [90]. The higher body clearance due to increased renal and nonrenal elimination $[76,88]$ demands that higher antibiotic doses are administered more frequently [87, 93]. However, differences between $\mathrm{CF}$ patients and non-CF individuals in this context do not seem to be as large as used to be thought and may have been exaggerated by the lack of properly matched controls for 
clinical studies [69]. The pharmacokinetics of ciprofloxacin are not altered in $\mathrm{CF}$ patients compared to non-CF individuals [94-96]. However, due to the basic defect, delayed absorption of oral antibiotics including ciprofloxaxin has been reported [91].

\section{Intravenous antipseudomonal antibiotic therapy in cystic fibrosis}

Mostly due to the endobronchial location of the $P$. aeruginosa infection in CF patients and the inaccessibility of mucoid $P$. aeruginosa in plugs, high doses of antibiotics have been recommended in CF patients (table 1). Nevertheless, optimal doses of various intravenously administered antibiotics in CF are debated. The initial doses of aminoglycosides may be calculated based on the body surface area [76] or body weight [64, 90, 93]. A theoretical calculation of the dosing of ceftazidime demonstrates that the previously recommended doses of $<200$ $\mathrm{mg} \cdot \mathrm{kg}^{-1}$ [97] may still be too low for treating CF patients [70] when given intermittently. Meropenem was given at a dose of $40 \mathrm{mg} \cdot \mathrm{kg}^{-1}$ [98] three times daily.

Intravenously administered aminoglycosides are usually given three times daily. Initial tobramycin dosages of $\sim 10$ $\mathrm{mg} \cdot \mathrm{kg}^{-1} \cdot \mathrm{day}^{-1}$ and more have been recommended [22, 64, $99,100]$. An adjustment in dose interval based on the serum tobramycin level has a significant effect on pulmonary function [93]. Due to the subinhibitory MIC effect [101], the bactericidal concentration-dependent killing and adaptive resistance, aminoglycosides might be administered in higher doses less frequently [102]. Indeed, 12 hourly high peak aminoglycoside dosing has been shown to be less toxic and equally efficacious as 8 hourly dosing [103]. Similarly, a study comparing once daily with thrice daily intravenous tobramycin suggested that once daily tobramycin combined with three injections of ceftazidime is safe and effective in CF [68]. To fully answer the question on efficacy and toxicity in this context, a multicentre study is currently being carried out in the UK. (A. Smyth, Dept of Paediatrics, Nottingham City Hospital, Nottingham, UK, personal communication). Since piperacillin has been repeatedly described to induce a serumsickness-like symptom [104-106], caution is needed when using this drug in high concentrations. Intravenous antibiotic therapy is generally scheduled for $\sim 2$ weeks but may also be prolonged for another week [99].

Courses with intravenously administered antibiotics have been shown, by most investigators, to be clinically effective. The effectiveness of the various penicillins seems to be similar [42]. From the third generation cephalosporins, ceftazidime particularly is effective against $P$. aeruginosa $[85,97]$. Similarly, no differences were found in effects on clinical condition, pulmonary function, or $P$. aeruginosa sputum counts when different aminoglycosides were compared with each other such as tobramycin with gentamicin or with netilmicin [42]. From a clinical viewpoint and depending on the local antimicrobial resistance patterns encountered most frequently, gentamicin appears the less desirable option.

Combination therapy with antibiotics has been favoured by several investigators because it may slow down drug resistance and may result in synergy. Often, a combination of a penicillin and an aminoglycoside is given. Genta- micin/carbenicillin, tobramycin/ticarcillin or amikacin/ceftazidime combinations have been widely used. Probenicid may be taken orally to enhance blood levels of some penicillins. Cefsulodin, piperacillin, imipenem, fosfomycin or aztreonam have been combined with tobramycin or amikacin [42]. Combinations of aminoglycosides with a cephalosporin such as ceftazidime or cefsulodin seem to be superior in their effect on pulmonary function, clinical situation and drug resistance compared to combinations with penicillins.

Also the combination of antipseudomonal antibiotics with antibiotics of less efficacy against this organism may lead to beneficial results. For example, in vitro the combination of high concentrations of ceftazidime and gentamicin with rifampicin, which has little activity against the strains, led to the elimination of $P$. aeruginosa from biofilms [107]. Whether macrolides such as azithromycin [108] are effective has to be investigated in future multicentre studies. In vitro studies showed an inhibitory activity of macrolides on the production of alginate and other virulence factors of $P$. aeruginosa [109].

Nevertheless, in some studies, monotherapy was superior to combination therapy. For example, when ticarcillin and tobramycin was compared to ceftazidime, clinical outcome was comparable, yet ceftazidime was more efficient to reduce $P$. aeruginosa colony counts in sputum specimens [58]. Similarly, ceftazidime alone showed better effectiveness than tobramycin and carbenicillin and better follow-up lung function values $[110,111]$. When azlocillin alone was compared to azlocillin and tobramycin [60] at the end of the treatment no significant difference was seen between the two groups in clinical evaluation, sputum DNA concentration, forced vital capacity, FEV1, or peak expiratory flow rate. However, sputum $P$. aeruginosa density decreased more with combination therapy and time to readmission for a new pulmonary exacerbation was significantly longer in the group receiving combination therapy [60]. Thus, little difference existed between antibiotics or their combinations concerning clinical condition, bacterial counts in sputum, leukocytes and chest radiographic findings [42]. Clinical studies evaluating the rational use of the combination of intravenous and aerosolized antibiotics in acute exacerbations are scarce and conclude that this combination therapy is not superior compared to intravenously administered therapy alone [69, 112-115].

CF patients are treated with antibiotics for most of their lives. Thus, any new or unusual symptom must be viewed with great suspicion as a possible drug side effect. The potential toxicities of aminoglycosides are similar and largely confined to the vestibular-auditory and renal systems [116] due to accumulation of the drug in cells where they bind to the ribosomes. Typical manifestations of ototoxicity such as loss of hair cells and degeneration of ganglion cells have been reported in CF patients [117, 118]. This may lead to high tone deafness and hypokalaemia or hypomagnesaemia [119]. Acute vestibular toxicity may be seen if the drug is given rapidly [102] and a long infusion is preferable. Some studies suggest tobramycin may be less nephrotoxic than gentamicin [119]. Administration of $15 \mathrm{mg} \cdot \mathrm{kg}^{-1} \cdot \mathrm{day}^{-1}$ of tobramycin [102] and netilmicin [120] has been associated with symptoms of dizziness after the antibiotic infusion. However, surprisingly few side-effects have been reported in high dose 
aminoglycoside therapy $[89,121,122]$. Nevertheless, it is necessary to monitor ototoxicity and renal function and adjust the dosage interval accordingly, early in therapy [64]. When meropenem was used in CF patients only transient elevations of serum transaminases have been reported and none of the patients experienced nausea and vomiting, even when meropenem was administered as a bolus injection [123].

Concerns have been raised on the potential toxicity of intravenous colistin. However, two studies reported a low frequency of nephrotoxicity $[73,74]$. The UK is the only known European country where colistin is given intravenously in CF patients. Whether other compounds present in the formulation of antibiotics such as phenol in the tobramycin preparation lead to toxicity is unknown. No written reports on side effects in this context have been collected by one of the manufacturers of tobramycin worldwide (J. Biclher, Lilly Germany, Bad Hamburg, Germany, personal communication). Penicillins contain large amounts of sodium, and caution is required in patients at risk of cor pulmonale. The addition of vitamin $\mathrm{K}$ to the daily regimen of patients on chronic or highdosage antibiotic therapy has been recommended [22]. More frequent are allergies against $\beta$-lactam antibiotics [124-126]. As a group penicillins had a higher frequency of allergic reactions than cephalosporins. The frequency of reactions has been shown to be greatest with acylaminopenicillins (azlocillin and piperacillin) and imipenem/ cilastatin [127]. The latter combination has not been recommended for routine treatment of CF patients with $P$. aeruginosa infection [128]. In CF patients with adverse reactions to ceftazidime or other $\beta$-lactam antibiotics, a desensitization regimen, starting at a very low dosage and increasing the dosage, has been proposed [129].

\section{Oral antipseudomonal antibiotic therapy in cystic fibrosis}

For obvious reasons, $\mathrm{CF}$ patients prefer oral treatment to intravenous therapy. As a result of the search for a useful oral treatment against $P$. aeruginosa, the fluoroquinolone ciprofloxacin was introduced in 1985. Early experience has been encouraging [71, 130-132]. Ciprofloxacin resulted in equal improvement in pulmonary function as treatment with azlocillin and gentamicin, and significant improvement was maintained at 6 weeks after ciprofloxacin treatment, which was not observed in a control group [130]. Statistically significant, stepwise changes in clinical scores, pulmonary function, and sputum concentrations of $P$. aeruginosa were noted, but regression toward initial values occurred by one week after treatment [132]. In a prospective, randomized, double blinded study comparing the efficacy and safety of ciprofloxacin versus ceftazidime/tobramycin in $P$. aeruginosa infected CF patients it was concluded that sequential intravenous/oral ciprofloxacin monotherapy offers a safe and efficacious alternative to standard parenteral therapy for acute pulmonary exacerbations in CF [133]. Oral ciprofloxacin therapy for 4 weeks has also been shown to prolong the beneficial effects of intravenous antibiotic therapy [134]. However, in seriously affected CF patients conventional treatment was significantly better than quinolone treatment [135].
The use of fluoroquinolones in children and accumulation of data on the pharmacodynamics of these drugs [66] have been limited and delayed by concerns regarding side effects, although adverse reactions were infrequent [132] and no serious side-effects were observed [130]. Animal studies showed that quinolones may negatively influence the cartilage [136] and therefore the use was restricted to patients after puberty. However, ultrasound examination and nuclear magnetic resonance imaging scans showed no evidence of cartilage toxicity in ciprofloxacin-treated $\mathrm{CF}$ patients $[133,137]$. A comprehensive review of the findings in animals compared with the cumulative published findings in children and adolescents allowed the conclusion that such concerns were not justified [138]. On this topic a consensus meeting has been held [139, 140]. Most experience is obtained with ciprofloxacin, other fluoroquinolones are less well tested in paediatric CF patients with pseudomonal respiratory tract infections. Gastrointestinal side effects, arthralgia in older CF patients with chronic $P$. aeruginosa infection, and occurrence of sleep disorders and psychotic episodes may be seen as well as photosensitivity reactions to sunshine.

Rapid emergence of resistance seems to be a much greater problem than side effects due to cartilage destruction [132]. However, initially, drug resistant organisms were isolated no more frequently after ciprofloxacin than after intravenous therapy with azlocillin and gentamicin. As with other drugs, clinical improvement in CF patients was achieved, regardless of the emergence of resistant $P$. aeruginosa $[130,132]$. However, experience with ciprofloxacin or other quinolones in children $<5 \mathrm{yrs}$ of age is very limited.

\section{Nebulized antipseudomonal antibiotic therapy in cystic fibrosis}

In an attempt to circumvent the problem of intravenously administered antibiotics penetrating into lung parenchymal tissue and bronchial secretions and their potential toxicity when given over prolonged periods of time, aerosolization of these drugs has been suggested. Indeed, this approach produced high lung concentrations and low serum levels of antibiotics [47, 141]. However, in general, aerosol delivery is a very inefficient method of delivering the antibiotics and even with the most efficient nebulizer, only a small proportion $(\sim 15-20 \%)$ of the medication is deposited in the lung; the remainder is either impacted on the oropharynx and swallowed, or exhaled into the surrounding atmosphere [142].

Several studies using aerosolized antibiotics in $\mathrm{CF}$ patients have been performed often with variable results $[33,45,50,51,141,143,144]$. Besides aminoglycosides (gentamicin [144], tobramycin [33, 44, 45, 47, 51] and $\beta$-lactam antibiotics (ceftazidime [50] carbenicillin [143]), combinations of both classes have been used $[50,60]$. Colistin has also been used [43, 145, 146]. The penicillins have been mostly avoided because of concerns regarding development of hypersensitivity, odour, effect on teeth and greater difficulty in nebulization.

Interpretation and comparison of many studies in this field is difficult because of the different designs, the wide range in the amount of the antibiotic used, and the possible carry-over effects in cross-over studies. Despite these methodological difficulties, most of the studies showed 
Table 2. - Definitions within the context of management of cystic fibrosis patients

\begin{tabular}{|c|c|}
\hline $\begin{array}{l}\text { Lung colonization } \\
\text { by } P \text {. aeruginosa }\end{array}$ & $\begin{array}{l}\text { Presence of } P \text {. aeruginosa in the bronchial tree without direct (inflammation, fever, etc.) or } \\
\text { indirect (specific antibody response)signs of infection and tissue damage. }\end{array}$ \\
\hline $\begin{array}{l}\text { Chronic lung colonization } \\
P \text {. aeruginosa }\end{array}$ & $\begin{array}{l}\text { Presence of } P \text {. aeruginosa in the bronchial tree for at least } 6 \text { months, based on at least three } \\
\text { positive cultures with at least one month in by intervals between them without direct (inflamma- } \\
\text { tion fever etc.) or in direct ( } \text { snecific antibody response) signs of infection and tissue damage. }\end{array}$ \\
\hline $\begin{array}{l}\text { Lung infection by } \\
\text { P. aeruginosa }\end{array}$ & $\begin{array}{l}\text { Presence of bacteria in the bronchial tree with direct (inflammation, fever etc.) or indirect } \\
\text { (specific antibody response) signs of infection and tissue damage. Infection can also be diagnosed } \\
\text { on the basis of a positive antibody response in at least two examinations for patients who do not } \\
\text { expectorate and present negative bacterial cultures. }\end{array}$ \\
\hline $\begin{array}{l}\text { Chronic lung infection by } \\
\text { P. aeruginosa }\end{array}$ & $\begin{array}{l}\text { Presence of } P \text {. aeruginosa in the bronchial tree for at least } 6 \text { months, based on at least three } \\
\text { positive cultures with at least one month intervals between them with direct (inflammation, fever } \\
\text { etc.) or indirect (specific antibody response) signs of infection and tissue damage. Chronic } \\
\text { infection can also be diagnosed on the basis of a positive antibody response in at least two } \\
\text { examinations for patients who do not expectorate and present negative bacterial cultures. }\end{array}$ \\
\hline Maintenance antibiotic therapy & $\begin{array}{l}\text { Prolonged, continuous or intermittent antibiotic therapy, given even if clinical symptoms are } \\
\text { discrete and signs of acute exacerbations of lung disease are absent. }\end{array}$ \\
\hline Prophylactic antibiotic therapy & $\begin{array}{l}\text { The use of antibiotic before } P \text {. aeruginosa has been detected in order to prevent colonization and } \\
\text { infection. }\end{array}$ \\
\hline Antibiotic therapy on & $\begin{array}{l}\text { The use of antibiotics only when symptoms and signs of acute exacerbations of lung disease are } \\
\text { present. }\end{array}$ \\
\hline
\end{tabular}

improved lung function [33, 45, 47, 50, 143, 144] or slowing of the deterioration of lung function $[33,44,51]$ in the active treatment group compared to placebo. Additionally, most studies report a reduction in the number of hospital admissions $[50,51,143,144]$ and some report on a reduction of $P$. aeruginosa numbers $[47,145]$. Only one study demonstrated a decrease in inflammation by treatment with aerosolized antibiotics [51]. A review of five randomized controlled trials $[33,43,50,143]$ showed benefit for nebulized antipseudomonal antibiotic therapy with no demonstrable adverse effects [147]. A multicentre study including $520 \mathrm{CF}$ patients in the USA demonstrated conclusively that chronic intermittent therapy with tobramycin improved lung function, and reduced hospitalization and concomitant intravenous therapy [33]. Aerosolized colistin in combination with oral ciprofloxacin has been shown to significantly postpone chronic $P$. aeruginosa infection in CF patients [72, $146]$ and to maintain pulmonary function during the year after inclusion compared with the control group, in which pulmonary function declined [72]. Similarly, tobramycin inhalation may prevent $P$. aeruginosa pulmonary infection in CF [148]. Results from a recent consensus conference on the use of aerosolized antibiotics in CF patients [149] and reviews [142, 147, 150] have been published.

Due to low serum levels of aerosolized drugs, systemic toxicity is possibly avoided. Nevertheless this depends on the doses administered. Aerosol administration of $400 \mathrm{mg}$ [151] or $600 \mathrm{mg}$ [47] tobramycin performed during tidal volume breathing manoeuvres did not lead to audiometric abnormalities or renal toxicity in CF patients $[47,152]$. Similarly, no signs of renal or ototoxicity were detected after long-term tobramycin aerosol therapy [44, 47, 51]. Nevertheless, with higher daily doses of aminoglycosides and other inhalation techniques, long-term safety studies are still required, applying more sensitive methods for the investigation of renal function.

Since tobramycin levels in serum samples of CF patients may vary considerably after aerosol treatment [152], general dose recommendations should not be followed but rather serum aminoglycoside concentrations monitored in patients given high doses [64]. Thus, the optimal dose to be aerosolized for the different antibiotics may differ from patient to patient. For colistin, 2 mega units twice daily have been recommended [12]. Monitoring by serum levels is not yet feasible. Dosing of aerosolized antibiotics also depend on clinical efficacy and microbial susceptibility.

Emergence of drug-resistance after aerosol therapy has been noticed in several studies [33, 45, 47, 143] although $P$. aeruginosa susceptibility was regained after drug-free time periods [47]. This led to the concept of intermittent dosing $[33,45]$. The effect of resistance on efficacy of more prolonged aerosol antibiotic therapy is unknown at present. Large amounts of the aerosolized antibiotics may also be swallowed and studies have been suggested to investigate the effects on the gastrointestinal flora during chronic administration [64]. Improved drug delivery to the lung may overcome this problem.

Caution has to be maintained when solutions of drugs in saline or water are prepared since hypotonic as well as hypertonic solutions may affect lung function leading to bronchoconstriction and inflammation [153-155]. Furthermore, the drug itself can induce bronchoconstriction. Consequently, the use of isotonic solutions and the control of lung function before and immediately after nebulization of the antibiotic as well as therapeutic intervention with bronchodilators has been suggested $[12,64$, $155,156]$. For instance, an isotonic solution of colistin is made by dissolving 2 mega units of colistin in $3 \mathrm{~mL}$ water and $3 \mathrm{~mL}$ physiological saline [12].

Antibiotics are usually aerosolized by nebulizing a solution of the drug, although dry powder inhalation has also been reported [157, 158]. A nebulized aerosol can be produced by an air jet or by ultrasonic sound waves. Nebulization times may be much shorter using ultrasonic devices than using jet nebulizers [64, 115, 159]. Nevertheless, aerosolized medications are still frequently administered by nebulizers. In CF, the nebulizer should produce particles in the range of $2-5 \mu \mathrm{m}$ in order to reach the smaller bronchioles. Particles too large $(>5 \mu \mathrm{m}$ do not reach the lower respiratory tract, whereas particles too small $(<1 \mu \mathrm{m}$ are exhaled [160]. Important characteristics of nebulizers which may affect performance include drug 
output, aerosol particle size, nebulization time, drug amount delivered to the patient, fill volume, flow, temperature, and humidity of the driving gas. A number of studies have been performed that address these issues $[115,159,161-171]$. In general, large differences were found in relation to these variables $[162,166,167,171-$ 173]. For instance, deposition of aerosols in the airways may differ between the nebulizers as shown in radioaerosol studies [163, 167, 169]. In one study, a mean of $7 \%$ of inhaled tobramycin dose reached the lungs, while only $16 \%$ of this pulmonary tobramycin was deposited peripherally. The greater the lung damage as indicated by FEV1 and Chrispin-Norman score, the smaller the proportion of pulmonary tobramycin that reached the periphery [165]. Suitable systems for nebulization of antibiotics are an active Venturi nebulizer (Hudson Respiratory Care, Temecula, CA, USA) with low flow compressor, Pari LC plus (Pari, Starnberg, Germany) and Pulmo Aide compressor (DeVilbiss, Somerset, PA, USA), or Ventstream (Inspired Medical Products, Pagham, UK) and CR50 (Medic-Aid, Pagham, UK) or Porta-Neb (Medic Aid, Romedic, Meersen, the Netherlands). Nebulization during inspiration alone, regulated by pressing a break key (e.g. using the Pari LC plus) helps to save drug.

Sputum may impair uniform deposition of antibiotics and decrease therapeutic effects [163]. In general, the distribution of a drug in the CF lung is not homogenous, but focal in the larger central lung areas $[164,174,175]$. Hence, it is quite conceivable that $\mathrm{CF}$ patients with mild disease and low sputum production improve the most from aerosol antibiotic therapy [51], suggesting that early antipseudomonal treatment with aerosolized antibiotics is most effective. Consequently, it has also been suggested that antibiotic aerosolization should be preceded by physiotherapy, bronchodilators [176], mucolytic agents [177, 178 ], $1 \% \mathrm{~N}$-acetylcysteine [179] or recombinant human deoxyribonuclease (rhDNase) [180]. Alternatively, mixing tobramycin with salbutamol is acceptable, and saves nebulization time [44]. However, some mucolytic drugs may adversely influence the activity of antibiotics [75, 181]. For example, binding of tobramycin to components of CF sputum was increased after rhDNase treatment [75].

Since many CF patients re-use their disposable jet nebulizers [166], hygienic problems related to microbial contamination may arise. Therefore, patients must be instructed how to clean and dry their nebulizers. Furthermore, exhaled antibiotics should be discharged through a tube to the outside air or trapped in a filter, in order not to contaminate the surroundings of the patient. In some hospitals it is recommended that inhalations are performed in a separate area [182]. With new nebulizers releasing the drug during the first part of inspiration only (adaptive aerosol delivery, e.g. Halolite), filtering or venting the antibiotic is not required as the drug is not released during expiration. A recent sputum culture should be used to determine resistance patterns and guide the choice of inhaled antibiotic.

\section{Antibiotic strategies against Pseudomonas aeruginosa}

The use of prophylactic antibiotics in an attempt to prevent infection or colonization has been suggested, since lung infections with other micro-organisms including viruses may pave the way for $P$. aeruginosa colonization and infection. Conversely, it is thought that the increased incidence of $P$. aeruginos $a$ is the result of more frequent use of antibiotics, since broad spectrum antibiotics may depress the normal pharyngeal flora and thereby lower the colonization resistance. Continuous prophylactic flucloxacillin in CF patients diagnosed early, was associated with improved clinical progress during the first two years of life [183]. Whether antistaphylococcal treatment increases the rate of $P$. aeruginosa infections is not known. No studies have yet been published using antibiotics with anti- $P$. aeruginosa activity to prevent $P$. aeruginosa colonization in CF. Such studies may be needed, particularly to investigate if anti- $P$. aeruginosa antibiotics may be successful and prevent $P$. aeruginosa colonization and infection during symptomatic virus infection.

To eradicate mucoid $P$. aeruginosa from CF airways in the chronic infection state has been shown to be virtually impossible. The major factor responsible for this unpleasant situation is the inability to achieve antibiotic concentrations in CF airways high enough to kill $P$. aeruginosa. This is in part a consequence of the viscous nature of the pus matrix and the bacterial polysaccharide (alginate) matrix surrounding many $P$. aeruginosa organisms. Both matrices contribute to a decreased penetration of antibiotics. Thus, only a reduction of $P$. aeruginosa colony counts can be generally achieved by antibiotic therapy in $\mathrm{CF}$ airways. This may lead to temporal undetectability of $P$. aeruginosa in sputum specimens after antibiotic therapy courses which may be interpreted as temporal eradication. However, when $P$. aeruginosa is recultured, genotyping may prove identity with the $P$. aeruginosa strain present before treatment, suggestive that the therapy did not lead to eradication but rather led to numbers of $P$. aeruginosa in the $\mathrm{CF}$ airways too low to be detected in vitro.

This has prompted trials with small numbers of $\mathrm{CF}$ patients in which antibiotic therapy was initiated shortly after the assessment of $P$. aeruginosa lung colonization $[146,148]$. At that time, the bacterium exhibits normally a nonmucoid phenotype and sputum volumes are low. In an open study, the combined treatment of aerosolized colistin and oral ciprofloxacin significantly reduced the onset of chronic $P$. aeruginosa infection in treated CF patients compared to untreated controls [146]. Similarly, a placebo controlled doubleblinded, randomized tobramycin inhalation study showed that after onset of $P$. aeruginosa colonization, the time of conversion to a $P$. aeruginosa negative respiratory culture was significantly shortened by active treatment, suggesting that early tobramycin inhalation may prevent $P$. aeruginosa pulmonary infection in CF [148]. In a follow-up study [72], it was demonstrated that aggressive treatment prevented or delayed chronic $P$. aeruginosa infection in $78 \%$ of the $\mathrm{CF}$ patients for $3.5 \mathrm{yrs}$. After introduction of early intensive antibiotic treatment, the probability of still not having developed chronic $P$. aeruginosa infection $7 \mathrm{yrs}$ after the first isolation of $P$. aeruginosa was $>80 \%$ [184]. Furthermore, aggressive treatment maintained or increased pulmonary function during the year after inclusion compared with the control group, in which pulmonary function declined [72].

Home therapy permits more normal activity for the $\mathrm{CF}$ patient including school attendance or continuing employment [185]. When ceftazidime was delivered via an 
infusion pump intravenously to adult $\mathrm{CF}$ patients at home for 3 weeks, prolonged clinical improvement was noted in $70 \%$ of the patients and the number of cultures positive for $P$. aeruginosa decreased significantly during antibiotic treatment [186]. In another study [187] it was concluded that home intravenous antibiotic therapy in CF patients was a feasible, cost-effective alternative to receive therapy in hospital. However, for home antibiotic therapy whether nebulized or intravenously administered, patient guidelines concerning hygiene and physiotherapy need to be established [188]. In addition, stringent quality control and assessment of effectiveness is mandatory. When a patient is acutely ill or is not responding to outpatient parameters, hospitalization is usually recommended for administration of intravenous antibiotics and intensive use of aerosols and postural drainage. The costs for home treatment versus hospital treatment may differ from country to country.

Home treatment gives the patient more independence and less disruption to school, work or family life, saves cost of a hospital bed. Patients may agree to earlier antibiotic intervention and have less fear of cross-infection. For home treatment, the clinician should have knowledge of the home circumstances and a home visit is essential. The necessary equipment should be monitored. The patient or carer should be carefully instructed and a first antibiotic course should always take place in the hospital under medical supervision for $1 \mathrm{~h}$ after the injection. Written instruction of what to do, and how to handle any side effects should be given and a $24 \mathrm{~h}$ telephone assistance should be provided. Venflon, longline or implantable intravascular devices should be used. Home treatment is not allowed for any patient with a history of anaphylaxis. Some centres issue home anaphylaxis kits, however, such a complication has not occurred to the knowledge of the clinicians at the consensus conference.

In $\mathrm{CF}$ patients suffering from chronic $P$. aeruginosa infection lung tissue damage is thought to occur by continuous inflammation. During acute exacerbations, the lung function may further decline. Based on lung function data, studies from Denmark [11, 189] and the USA, indicate a positive effect on patients treated with intravenous antibiotics with specific activity against $P$. aeruginosa when given 3-4 times a yr either regularly as "maintenance therapy" or in comparison to administration for acute exacerbations as "on demand" therapy. Due to continuous inflammation, a slow decline of lung function is observed in patients also in between courses of intravenous antibiotics. This decline can be reduced by daily treatment with aerosolized antibiotics such as colistin and tobramycin. Alternatively a new approach of using preservative free tobramycin in a month on/month off fashion has been shown to be superior in terms of lung function than standard care in the USA (which included intravenous treatment on demand during exacerbations) [33]. Regardless of whether or not the patients experienced exacerbations for which they received intravenous antipseudomonal antibiotics, the FEV1 predicted of patients receiving placebo, decreased steadily during the pivotal trials [25]. The benefits to lung function observed following initiation of preservative free tobramycin therapy were similar among patients with and without symptoms requiring treatment with intravenous antipseudomonal antibiotics.
Concerns that intensive and aggressive antibiotic treatment may eventually result in the occurrence of multiresistant $P$. aeruginosa strains [53, 190], increased antibiotic toxicity or that such a treatment is very costintensive and may therefore only be applied to some CF patients [191], was not regarded as valid in this context by the members of the consensus meeting.

Provided that $P$. aeruginosa is sensitive to the antibiotic(s) used, there is broad scientific evidence that antibiotics administered intravenously, orally or by nebulization are clinically effective in CF patients. At best, these treatment strategies can reduce the number of exacerbations, hospital admissions and numbers of $P$. aeruginosa colonies in CF airways. In addition, early treatment of intermittent colonization of $P$. aeruginosa by the combination of a systemic antibiotic and the inhalation of an antibiotic may delay the onset of chronic $P$. aeruginosa infection.

A direct comparison of the different administration strategies, however, is difficult. Furthermore, some drugs with high activity against $P$. aeruginosa e.g. colistin are preferentially, but not exclusively [73], given by the aerosol route, whereas others e.g. ceftazidime, are preferentially given intravenously. Based on clinical efficacy, it is thus difficult to choose a given route and other criteria should be evaluated in order to reach an consensus on the optimal treatment strategy. These other criteria include: 1) development of microbial resistance to the $\operatorname{drug}(\mathrm{s}) ; 2)$ drug toxicity; 3) quality of life; and 4) feasibility for the patient. Aerosol delivery of antibiotics to $P$. aeruginosa infected CF patients has been suggested as maintenance treatment.

It is highly recommended that the antibiotic is chosen on the basis of resistance pattern of the microorganisms. The use of a given drug with activity against $P$. aeruginosa may also differ from country to country. Thus, colistin is used for inhalation therapy in the UK, Italy, France, The Netherlands and Denmark, whereas in Germany tobramycin is used more commonly. An epidemiological study showed that in France the antibiotics most frequently prescribed were colistin (500,000 to 3 MIU per aerosol), tobramycin (25-600 mg per aerosol) and amikacin (150 $\mathrm{mg}$ to $1.5 \mathrm{~g}$ per aerosol) reflecting the frequent use of nebulizers [192]. In the UK and Eire, $P$. aeruginosa acute exacerbations are treated with a combination of penicillins with aminoglycosides by $76.9 \%$ of physicians, whereas $19.2 \%$ regularly use intravenous monotherapy with ceftazidime. As an alternative, when intravenous therapy is considered inappropriate, oral ciprofloxacin is sometimes used by all clinicians. For maintenance of lung function in $P$. aeruginosa infected CF patients all physicians used nebulized antibiotics, the indications for which vary between CF centres [193].

In general, there is no consensus on the dosage for the different antibiotics. However, high doses of drugs should be given in order to maximize reduction in P. aeruginosa colony counts and increase lung function.

The duration of therapy, once initiated, varies considerably. Most decisions are empirical and are based in part on age, severity of disease and past experience. In general, most patients show improvement well into the second week of therapy. Weekly pulmonary function testing and clinical observations are used for the decision when to end hospitalization. If further improvement seems possible, therapy is extended into the third week. 
Future antibiotic treatment studies against Pseudomonas aeruginosa in infected cystic fibrosis patients

Although much has been achieved, there is still the need to fill the gaps in the knowledge on antibiotic therapy for $P$. aeruginosa lung infection in CF patients. This concerns indications for antibiotic therapy, the antibiotics used, or the dosage schedules. Therefore, further studies need to be planned. However, designs of such trials are complicated. Well defined indications and objectives, together with valid outcome measures, will be decisive for the choice of the appropriate (randomized, double-blind or single-blind) design and duration of a study. See for example the list of issues below which need to be studied. Lung function parameters and local inflammation parameters are useful for the assessment of antibiotic efficacy in clinical trials [194]. Attention to matching of patients for severity should be considered. Studies are required to determine if the dose of antibiotics can be indicated by their activity in the sputum. The distribution and half-life of antibiotics in pulmonary secretions should also be studied. The progressive nature of the disease, the large heterogeneity of the clinical status, the variability of the therapy regimens in single CF centres and other difficulties can better be controlled for in large randomized clinical studies. Prescribing strategies may differ from country to country. Multicentre, preferably pan European, studies are recommended $[195,196]$. Such studies will require a well organized research network, which will minimise the barriers across the boarders; the limited number of study patients is a strong reason to be as efficient as possible in organizing such trials. Studies intending to seek approval of an indication or dosing regimen, within the context of drug registration, need to take the available regulatory guidelines into consideration. A well structured research incentive in CF patients will also need to be supported by funds from public health authorities and industry.

\section{Appendix: important questions and answers}

Definitions can be seen in table 2 .

1. How, when, and how often should $P$. aeruginosa lung colonization or lung infection be assessed in $\mathbf{C F}$ patients?

Consensus: $P$. aeruginosa lung infection in CF patients should be assessed by taking sputum with as little contamination of saliva as possible. In nonsputum producers, hypopharyngeal or endolaryngeal suctions should be taken preferably after lung physiotherapy or alternatively after hypertonic saline inhalation. In nonsputum producers periodic serological tests for $P$. aeruginosa antigens should be used to avoid false-negative results from bacterial culturing. Microscopy of Gram stained smears is recommended to detect neutrophils and micro-organisms and disregard specimens dominated by squamous epithelial cells. $P$. aeruginosa colonization/infection should be assessed as early as possible, on every routine visit of the patient at the CF centre, preferentially at least every three months.
2. Does $P$. aeruginosa lung infection accelerate the decrease in lung function in CF patients?

Consensus: some patients characterized by harbouring nonmucoid $P$. aeruginosa strains, absent or low antibody titers to the organisms and absent or little sputum production can tolerate $P$. aeruginosa colonization for years without decline in lung function. However, in the majority of CF patients carrying mucoid $P$. aeruginosa, the infection causes an immediate and more rapid reduction of lung function than in $\mathrm{CF}$ patients without $P$. aeruginosa infection.

\section{Is antibiotic therapy for $P$. aeruginosa lung infection needed and does it affect survival in CF patients?}

Consensus: in general antipseudomonal therapy is warranted in CF patients. It affects survival of the patients to an unknown extent, since $\mathrm{CF}$ patients are treated with drugs other than antibiotics.

4. How should $P$. aeruginosa susceptibility against antibiotics be assessed and how should the results be used?

Consensus: for testing antibiotic susceptibility, the plate diffusion method should be the standard for practical purposes. Micro-dilution methods should only be used on specific requests by the clinician, e.g. in clinical trials or on an annual basis to document the levels of bacterial resistance against the antibiotics used in the $\mathrm{CF}$ centre. Quantitative $P$. aeruginosa counts in the sputum culture are not needed in routine diagnostic. Certain subpopulations of $P$. aeruginosa may take longer than $48 \mathrm{~h}$ to grow. The results of antibiotic susceptibility should guide the clinician to use the antibiotics to which $P$. aeruginosa is most sensitive. $P$. aeruginosa strains revealing different antibiotic sensitivity patterns in one patient sample should be treated with combinations of antibiotics which act synergistically. Similarly, pan-resistant organisms should be treated with antibiotic combinations based on the patient's previous clinical response.

\section{Does drug resistance influence antibiotic therapy regimes?}

Consensus: although antibiotic treatment may lead to the growth of resistant strains, the resistant strains may not have the same degree of pathogenicity as the dominant sensitive strains. Results from bacterial antibiotic resistance testing should influence antibiotic choices. In general, high antibiotic dosages are recommended to maximise drug concentration in the lungs and to minimise the risk of the development of bacterial resistance.

6. Does combination therapy with two different drugs delay antibiotic resistance compared to monotherapy?

Consensus: combination therapy with two different drugs delays antibiotic resistance compared to monotherapy. 
7. Does antibiotic therapy lead to selection of intrinsically resistant pathogens?

Consensus: clinical experience on the selection of intrinsically resistant pathogen during antibiotic therapy varies and more long term evidence and more detailed analysis of any evidence both in inhalation and intravenous antibiotic therapy is needed.

\section{How are optimal airway concentrations of antibiotics} obtained?

Consensus: optimal airway concentrations of antibiotics are obtained by individually tailoring doses for each patient which can be given intravenously, orally or by inhalation. Because of lack of data, the optimal route to achieve suitable airway concentrations is unclear and clinical indications determine the route of administration: 1) eradication of early $P$. aeruginosa colonization/infection (inhaled with and without oral antibiotic therapy); 2) maintenance therapy (inhaled antibiotic therapy without and with intravenous antibiotic therapy); and 3) acute exacerbations with multiresistant $P$. aeruginosa (intravenous antibiotic therapy).

9. Do even subinhibitory concentrations of antibiotics produce beneffcial effects in CF airways?

Consensus: subinhibitory concentrations of antibiotics may have beneficial effects on $P$. aeruginosa pathogenicity. However there may be also unwanted effects, such as increased mutation rates and the production of adaptive resistance to aminoglycosides in $P$. aeruginosa. The ultimate effect is unclear.

\section{Do the pharmacokinetics of antibiotics in $C F$ patients differ from that in non-CF individuals?}

Consensus: CF patients may differ from healthy individuals in the pharmacokinetics of certain antibiotics. However, this may be due to differences in body composition rather than the basic defect of $\mathrm{CF}$.

11. With which doses and dosing intervals and for how long CF patients should be treated with intravenously administred antibiotics?

Consensus: antibiotics, doses, dosing intervals and duration of treatment given in table 1 of this document are recommended whenever appropriate. The minimum length of intravenous antibiotic treatment should be $\sim 2$ weeks; however there is little published data to support this.

\section{Is combination therapy with two different drugs} superior to monotherapy?

Consensus: with a susceptible bacterial strain, monotherapy may be as effective as combination therapy. However, with a resistant strain of $P$. aeruginosa, combination therapy is more effective. Combination therapy is encouraged because of the risk of development of bacterial resistance if monotherapy is continued over several courses.

\section{Does repeated intravenous antibiotic therapy lead to toxic side effects in $\mathrm{CF}$ patients?}

Consensus: aminoglycosides may cause ototoxicity and nephrotoxicity, however, surprisingly little side effects have been reported in high dose aminoglycoside therapy. Intravenously administered colistin was reported to cause only a low frequency of nephrotoxicity. $\beta$-lactam antibiotics may cause drug hypersensitivity.

\section{Should fluoroquinolones be used in children with} $\mathrm{CF}$ and at which doses?

Consensus: certain fluoroquinolones such as ciprofloxacin can be used in CF patients including children, however, experience in children $<5$ yrs of age is very limited to allow a general recommendation. Severe skin photosensibility can be prevented by use of sun-block lotions. Side effects disappear after treatment is finished and no persistent damage has been observed. Resistance to quinolones occurs as to any other antibiotics.

\section{Is administration of nebulized antibiotics clinically effective?}

Consensus: administration of nebulised antibiotics is clinically effective. When given to patients chronically infected with $P$. aeruginosa, it may improve lung function and reduce the incidence of acute exacerbations. All patients chronically infected with mucoid $P$. aeruginosa should be offered this treatment irrespective of lung function. Nebulized antibiotics are beneficial if given at the first isolation of $P$. aeruginosa in delaying chronic infection. There is no evidence that they are effective in the treatment of acute exacerbations.

16. What are the side effects of nebulized antibiotic therapy, what are the antibiotic doses to be administered and does resistance of $\boldsymbol{P}$. aeruginosa against highdose nebulized antibiotics develop after treatment courses?

Consensus: the major side effect of nebulized antibiotic therapy is bronchospasm. There is no evidence of renal toxicity or auditory toxicity when inhaled antibiotics are used alone. However, caution is needed when patients receive intravenously administered aminoglycosides in addition to high dose aerosolized antibiotics. No comparative dose studies are available. Tobramycin $300 \mathrm{mg}$ b.i.d. on alternative months is safe over a two year period. Daily colistin 1 mega unit bid or tobramycin $80 \mathrm{mg}$ b.i.d. or 160 $\mathrm{mg}$ b.i.d. is safe. Resistance of $P$. aeruginosa against highdose nebulized tobramycin antibiotics may develop, but does not seem to be clinically important. There is little evidence of resistance to colistin. There is a need to obtain evidence concerning toxicity from long-term follow-up studies of patients who are taking inhaled antibiotics.

\section{How should antibiotics be inhaled?}


Consensus: patients must be instructed how to clean and dry their nebulizer. Drugs should be inhaled using a nebulizer and air compressor system that produces the majority of aerosol particles at a mass medien aerodynamic diameter of $2-5 \mu \mathrm{m}$. The nebulization time should be short to encourage compliance. A filter or venting of antibiotics to the outside air is advisable. Patients should be tested for a bronchial constriction effect when started on a new inhaled antibiotic. Some patients benefit from taking a bronchodilator before inhaling the nebulized antibiotic on a regular basis.

18. Is prevention of $P$. aeruginosa lung colonization possible in CF using prophylactic antibiotic therapy?

Consensus: due to lack of prophylactic studies using antibiotics with anti- $P$. aeruginosa activity, preventive antibiotic strategies are not recommended.

\section{Can antibiotic treatment prevent early colonization or delay the onset of chronic $P$. aeruginosa infection in CF?}

Consensus: early anti- $P$. aeruginosa treatment of initial $P$. aeruginosa colonization can delay the onset of chronic $P$. aeruginosa infection. In many patients the treatment has to be repeated due to recurrent colonization. The long-term clinical outcome of this early treatment is not sufficiently known.

\section{Antibiotic therapy at home or in the hospital: what is recommended?}

Consensus: both antibiotic therapy at home or in the hospital is recommended whenever appropriate since both locations have advantages and disadvantages. Hospital treatment provides better physiotherapy, treatment of complications and dieticians advice. It gives the patient and/or the family a rest and is essential for severely ill patients, patients with anaphylaxis or patients with unfavourable social/economic circumstances.

\section{Regular maintenance treatment or treatment on demand: what is recommended?}

Consensus: CF patients suffering from chronic P. aeruginosa infection should be treated with antibiotics with specific activity against $P$. aeruginosa either 3-4 times a year intravenously or by appropriate aerosol administration using either colistin or tobramycin throughout the year. Any acute exacerbation should be treated with appropriate antibiotics.

\section{Which route of administration of antibiotics is} recommended?

Consensus: answers to this question depend on the clinical situation. For maintenance therapy the inhalation route is strongly suggested. For the treatment of moderate to severe acute exacerbations, intravenous administration of two different classes of antibiotics is suggested. There is no available evidence which supports the addition of aerosol therapy for routine treatment of acute exacerbations. For exacerbations, also oral ciprofloxacin may be appropriate. For eradication therapy of a first or intermittent $P$. aeruginosa colonization, treatment strategies include immediate colistin or tobramycin inhalation combined with oral ciprofloxacin. In case that inhalation and oral therapy fails, patients should be immediately treated with intravenously administered antibiotics.

23. Which factors determine the choice of the antibiotic, the dosage, and the duration of the treatment in CF patients?

Consensus: the choice of an antibiotic is based on the susceptibility patterns of the microorganism and the occurrence of previous side effects. Recommended doses are listed in the table of this document. The cheapest alternative is recommended. High dosages of antibiotics should be used and levels of aminoglycosides monitored weekly. For intravenous therapy, the standard length of treatment should be 14 days which may be prolonged in special cases, i.e. in severe exacerbations or incomplete recovery. Suggested end points for treatment are respiratory function, weight, the overall clinical state and inflammatory markers.

\section{What is the design of future antibiotic studies in the context of $P$. aeruginosa lung infection in CF patients?}

Consensus: future studies should deal with: Different antibiotic dosage for both intravenous and inhaled administration; daily treatment versus treatment every second month for inhaled antibiotics; inhaled antibiotic versus inhaled antibiotics plus oral quinolones; different dose frequency (once, twice or three times daily) for intravenous antibiotic therapy; the use of antibiotics in acute exacerbations. It is needed to study one antibiotic, plus two antibiotics given intravenously, and also one antibiotic given intravenously with another given by inhalation; the efficacy of colistin versus tobramycin for inhalation; the effects of early treatment, long-term follow-up of high dose (300 $\mathrm{mg}$ ) tobramycin b.i.d. and rotating inhaled antibiotics; the devlopment of improved nebulisers to shorten treatment time including dry powder inhalers; long-term antibiotic studies; and treatment on demand versus maintenance therapy in chronic infection.

F. Baquero, Servicio de Microbiologia, Hospital Ramon y Cajal, Madrid, Spain; A. Bauernfeind, MICOER, München, Germany; E. BergogneBérézin, Service de Microbiologie, CHU Bichat Claude-Bernard, Paris, France; R. Bertele-Harms, Dr. von Haunersches Kinderspital der Universität München, München, Germany; D. Bilton, Adult Cystic Fibrosis Centre, Papworth Hospital NHS Trust, Cambridge, UK; D. Costantini, Clinica Pediatrica II della Universita di Milano, Milano, Italia; F. J. Dapena, Unidad de Fibrosis Quistica, Hospitales Universitarios Virgen del Rocio, Sevilla, Spain; S. Elborn, Belfast City Hospital, Adult Cystic Fibrosis Centre, Belfast, Northern Ireland, UK; M. Götz, Abteilung für Kinder- und Jugendheilkunde mit Infektionskrankheiten, Wilhelminenspital, Wien, Austria; H.K. Harms, Dr. von Haunersches Kinderspital der Universität München, München, Germany; C. Koch, Dept of Pediatrics, Danish Cystic Fibrosis Centre, National University Hospital, Copenhagen, Denmark; P. A. Lambert, Aston University, Birmingham, UK; H. Lindemann, Zentrum für Kinderheilkunde, Universität Gieben, Germany; G. Mastella, Ospedale di Borgo Trento, Verona, Italia; S. 
Mukhopadhyay, Ninewells Hospital, Dept of Child Health, University of Dundee, Dundee, Scotland, UK; J. Navarro, Service de Gastroentérologie et Nutrition Pédiatriques, Hopital Robert Debre, Paris, France; W. Nikolaizik, Klinik und Poliklinik für Kinder- und Jugendmedizin, Universitätsklinikum Essen, Essen, Germany; H.-G. Posselt, Abt. Allgemeine Pädiatrie I, Zentrum für Kinderheilkunde, Klinikum der Johann Wolfgang Goethe-Universität, Frankfurt, Germany; L. Romano, Istituto Giannina Gaslini, Genova, Italia; H.C. Ryley, Dept of Medical Microbiology, University of Wales, Cardiff, Wales, UK; U.B. Schaad, UniversitätsKinderspital beider Basel, Basel, Switzerland; S. Simonian, Medicine Evaluation Board, The Hague, the Netherlands; A.L. Smith, Molecular Microbiology and Immunology, University of Missouri-Columbia, Columbia, USA; G. Steinkamp, Hannover, Germany; G. Taccetti, Dipartimento di Pediatria, "Cesare Cocchi" Ospedale Meyer, Firenze, Italia; D. Turck, Clinique de Pediatrie, Hopital Jeanne de Flandre, Lille, France; P. H. Weller, Dept of Respiratory Medicine, and Cystic Fibrosis, Birmingham Children's Hospital, Birmingham, UK.

\section{References}

1. Lewis PA. The epidemiology of cystic fibrosis. In: Hodson ME, Geddes D, eds. Cystic Fibrosis. London, Chapman and Hall, 1995; pp. 1-13.

2. Santis G. Basic molecular biology. In: Hodson ME, Geddes D, eds. Cystic Fibrosis. London, Chapman and Hall, 1995; pp. 15-39.

3. Sheppard MN. The pathology of cystic fibrosis. In: Hodson ME, Geddes D, eds. Cystic Fibrosis. London, Chapman and Hall, 1995; pp. 131-149.

4. Armstrong DS, Grimwood K, Carlin JB, et al. Lower airway inflammation in infants and young children with cystic fibrosis. Am J Respir Crit Care Med 1997; 156: 1197-1204.

5. Anonymous. Cystic fibrosis foundation patient registry 1997 annual data report. Bethesda, MD, USA. Cystic Fibrosis Foundation 1998.

6. Khan TZ, Wagener JS, Bost T, Martinez J, Accurso FJ, Riches DWH. Early pulmonary inflammation in infants with cystic fibrosis. Am J Respir Crit Care Med 1995; 151: 1075-1082.

7. Sabath LD, ed. Pseudomonas aeruginosa, the organism, diseases it causes, and their treatment. Bern, Hans Huber Publishers, 1980.

8. Botzenhart K, Döring G. Epidemiology and ecology of Pseudomonas aeruginosa. In: Campa M, Bendinelli M, Friedman H, eds. Pseudomonas aeruginosa as an opportunistic pathogen. New York, Plenum Press, 1993; pp. $1-18$.

9. Høiby N. Microbiology of lung infections in cystic fibrosis patients. Acta Paediatr Scand Suppl 1982; 301: 33-54.

10. Stern M, Döring G, Eißing G, et al. Qualitätssicherung Mukoviszidose. Zentrum für Qualitätsmanagement im Gesundheitswesen. Ärztekammer Niedersachsen, Postfach 4749, 30047 Hannover, 1997.

11. Høiby N, Koch C. Pseudomonas aeruginosa infection in cystic fibrosis and its management. Thorax 1990; 45: 881-884.

12. Webb AK, Dodd ME. Nebulised antibiotics for adults with cystic fibrosis. Thorax 1997; 52: S69-S71.

13. Cryz SJ Jr. Pseudomonas aeruginosa vaccines. In: Cryz SJ Jr, ed. Vaccines and Immunotherapy. New York, Pergamon Press, 1991; pp. 156-165.

14. Langford DT, Hiller J. Prospective, controlled study of a polyvalent pseudomonas vaccine in cystic fibrosis - three year results. Arch Dis Child 1984; 59: 1131-1133.

15. Pennington JE, Reynolds HY, Wood RE, Robinson RA,
Levine AS. Use of a Pseudomonas aeruginosa vaccine in patients with acute leukemia and cystic fibrosis. $\mathrm{Am} J$ Med 1975; 58: 629-636.

16. Lang AB, Schaad UB, Rudeberg A, et al. Effect of highaffinity anti-Pseudomonas aeruginosa lipopolysaccharide antibodies induced by immunization on the rate of Pseudomonas aeruginosa infection in patients with cystic fibrosis. J Pediatr 1995; 127: 711-717.

17. Döring G, Dorner F. A multicenter vaccine trial using the Pseudomonas aeruginosa flagella vaccine IMMUNO in patients with cystic fibrosis. Behring Inst Mitt 1997; 98: 338-344.

18. Matsui H, Grubb BR, Tarran R, et al. Evidence for periciliary liquid layer depletion, not abnormal ion composition, in the pathogenesis of cystic fibrosis airways disease. Cell 1998; 5: 1005-1015.

19. Cabral DA, Loh BA, Speert DP. Mucoid Pseudomonas aeruginosa resists nonopsonic phagocytosis by human neutrophils and macrophages. Pediatr Res 1987; 22: 429431.

20. Döring G, Knight R, Bellon G. Immunology of cystic fibrosis. In: Morlin ME, Hedges GL, Smith AL, Burns JL, eds. Cystic Fibrosis. Accuracy and cost of antibiotic susceptibility testing of mixed morphotypes of Pseudomonas aeruginosa. J Clin Microbiol 1994; 32: 1027-1030.

21. Høiby N. Microbiology of cystic fibrosis. In: Hodson M, Geddes D, eds. Cystic Fibrosis. London, Chapman and Hall, 1995; pp. 76-98.

22. Gilligan PH. Pseudomonas and Burkholderia. In: Murray PR, Baron EJ, Pfaller MA, Tenover FC, Yolken RH, eds. Manual of Clinical Microbiology. 6th ed. Washington, DC, ASM Press, 1995; pp. 509-519.

23. Thomassen MJ, Demko CA, Doershuk CF. Cystic fibrosis: a review of pulmonary infections and interventions. Pediatr Pulmonol 1987; 3: 334-351.

24. Häußler S, Tümmler $\mathrm{B}$, Weißbrodt $\mathrm{H}$, Rohde $\mathrm{M}$, Steinmetz I. Small-colony variants of Pseudomonas aeruginosa in cystic fibrosis. Clin Infect Dis 1999; 29: 621-625.

25. Ramsey BW, Wentz KR, Smith AL, et al. Predictive value of oropharyngeal cultures for identifying lower airway bacteria in cystic fibrosis patients. Am Rev Respir Dis 1991; 144: 331-337.

26. Döring G, Høiby N. Longitudinal study of immune response to Pseudomonas aeruginosa antigens in cystic fibrosis. Infect Immun 1983; 42: 197-201.

27. Kerem E, Corey M, Stein R, Gold R, Levison H. Risk factors for Pseudomonas aeruginosa colonization in cystic fibrosis patients. Pediatr Infect Dis J 1990; 9: 494-498.

28. Sharma GD, Tosi MF, Stern RC, Davis PB. Progression of pulmonary disease after disappearance of Pseudomonas in cystic fibrosis. Am J Respir Crit Care Med 1995; 152: 169-173.

29. Corey M, Farewell V. Determinants of mortality from cystic fibrosis in Canada, 1970-1989. Am J Epidemiol 1996; 143: 1007-1017.

30. Kerem E, Corey M, Gold R, Levison H. Pulmonary function and clinical course in patients with cystic fibrosis after pulmonary colonization with Pseudomonas aeruginosa. J Pediatr 1990; 116: 714-719.

31. Gold R, Carpenter S, Heurter H, Corey M, Levison H. Randomized trial of ceftazidime versus placebo in the management of acute respiratory exacerbations in patients with cystic fibrosis. J Pediatr 1987; 111: 907-913.

32. Wolter JM, Bowler SD, McCormack JG. Are antipseudomonal antibiotics really beneficial in acute respiratory 
exacerbations of cystic fibrosis? Aust NZ J Med 1999; 29: $15-21$.

33. Ramsey BW, Pepe MS, Quan JM, et al. Intermittent administration of inhaled tobramycin in patients with cystic fibrosis. Cystic Fibrosis Inhaled Tobramycin Study Group. N Engl J Med 1999; 340: 23-30.

34. Regelmann WE, Elliott GR, Warwick WJ, Clawson CC. Reduction of sputum Pseudomonas aeruginosa density by antibiotics improves lung function in cystic fibrosis more than do bronchodilators and chest physiotherapy alone. Am Rev Respir Dis 1990; 141: 914-921.

35. Frederiksen B, Lanng S, Koch C, Høiby N. Improved survival in the Danish center-treated cystic fibrosis patients: results of aggressive treatment. Pediatr Pulmonol 1996; 21: 153-158.

36. Weiss K, Lapointe JR. Routine susceptibility testing of four antibiotic combinations for improvement of laboratory guide to therapy of cystic fibrosis infections caused by Pseudomonas aeruginosa. Antimicrob Agents Chemother 1995; 39: 2411-2414.

37. Burns JL, Van-Dalfsen JM, Shawar RM, et al. Effect of chronic intermittent administration of inhaled tobramycin on respiratory microbial flora in patients with cystic fibrosis. J Infect Dis 1999; 179: 1190-1196.

38. Ceri H, Olson ME, Stremick C, Read RR, Morck D, Buret A. The Calgary Biofilm Device: new technology for rapid determination of antibiotic susceptibilities of bacterial biofilms. J Clin Microbiol 1999; 37: 1771-1776.

39. Shawar RM, MacLeod DL, Garber RL, et al. Activities of tobramycin and six other antibiotics against Pseudomonas aeruginosa isolates from patients with cystic fibrosis. Antimicrob Agents Chemother 1999; 43: 2877-2880.

40. Giwercman B, Meyer C, Lambert PA, Reinert C, Høiby N. High-level betalactamase activity in sputum samples from cystic fibrosis patients during antipseudomonal treatment. Antimicrob Agents Chemother 1992; 36: 7176.

41. Krilov LR, Blumer JL, Stern RC, Hartstein AI, Iglewski $\mathrm{BN}$, Goldmann DA. Imipenem/cilastatin in acute pulmonary exacerbations of cystic fibrosis. Rev Infect Dis 1985; 7: S482-S489.

42. Michel BC. Antibacterial therapy in cystic fibrosis. A review of the literature published between 1980 and February 1987. Chest 1988; 94: 129S-140S.

43. Jensen T, Pedersen SS, Garne S, Heilmann C, Høiby N. Koch C. Colistin inhalation therapy in cystic fibrosis patients with chronic Pseudomonas aeruginosa lung infection. J Antimicrob Chemother 1987; 19: 831-838.

44. MacLusky I, Gold R, Corey M, Levison H. Long-term effects of inhaled tobramycin in patients with cystic fibrosis colonized with Pseudomonas aeruginosa. Pediatr Pulmonol 1989; 7: 42-48.

45. Ramsey BW, Dorkin HL, Eisenberg JD, et al. Efficacy of aerosolized tobramycin in patients with cystic fibrosis. N Engl J Med 1993; 328: 1740-1746.

46. Ashby BL, Stern DH. Aerosolized tobramycin in patients with cystic fibrosis. N Engl J Med 1993; 329: 1659-1660.

47. Smith AL, Ramsey BW, Hedges DL, et al. Safely of aerosol tobramycin administration for 3 months to patients with cystic fibrosis. Pediatr Pulmonol 1989; 7: 265271.

48. Van Dalfsen JM, Lin L. Microbology effect at 18 months of intermittant inhaled tobramycin in patients with CF. Netherlands J Med 1999; 54: S39.

49. Barclay ML, Begg EJ, Chambers ST, Thornley PE, Pattemore PK, Grimwood K. Adaptive resistance to tobramycin in Pseudomonas aeruginosa lung infection in cystic fibrosis. J Antimicrob Chemother 1996; 37: 11551164.

50. Stead RJ, Hodson ME, Batten JC. Inhaled ceftazidime compared with gentamicin and carbenicillin in older patients with cystic fibrosis infected with Pseudomonas aeruginosa. Br J Dis Chest 1987; 81: 272-279.

51. Steinkamp G, Tümmler B, Gappa M, et al. Long-term tobramycin therapy in cystic fibrosis. Pediatr Pulmonol 1989; 6: 91-98.

52. Taccetti G, Campana S, Marianelli L. Multiresistant nonfermentative gram-negative bacteria in cystic fibrosis patients: the results of an Italian multicenter study. Italian Group for Cystic Fibrosis microbiology. Eur J Epidemiol 1999; 15: 85-88.

53. Ciofu O, Giwercman B, Pedersen SS, Høiby N. Development of antibiotic resistance in Pseudomonas aeruginosa during two decades of antipseudomonal treatment at the Danish CF Center. APMIS 1994; 102: 674-680.

54. Prince A. Antibiotic resistance of Pseudomonas aeruginosa. J Pediatr 1986; 108: 830-834.

55. Cheng K, Smyth RL, Govan JR, et al. Spread of betalactam-resistant Pseudomonas aeruginosa in a cystic fibrosis clinic. Lancet 1996; 348: 639-642.

56. Watkins J, Francis J, Kuzemko JA. Does monotherapy of pulmonary infections in cystic fibrosis lead to early development of resistant strains of Pseudomonas aeruginosa? Scand J Gastroenterol Suppl 1988; 143: 81-85.

57. Lietman PS. What is an antibiotic? J Pediatr 1986; 108 : 824-829.

58. Gold R, Overmeyer A, Knie B, Fleming PC, Levison H. Controlled trial of ceftazidime vs. ticarcillin and tobramycin in the treatment of acute respiratory exacerbations in patients with cystic fibrosis. Pediatr Infect Dis 1985; 4: 172-177.

59. Høiby N, Heilesen A, Moller NE. Development of Pseudomonas aeruginosa strains resistant to carbenicillin, azlocillin, piperacillin and tobramycin during chemotherapy in cystic fibrosis patients. In: Schöni M, Krachner R, ed. Current problems and trends in Cystic Fibrosis. Immunology and Antibiotic Treatment. Monogr Paediatr. Vol 14. Basel, Karger, 1981; pp. 103-107.

60. Smith AL, Doershuk C, Goldmann D, et al. Comparison of a beta-lactam alone versus beta-lactam and an aminoglycoside for pulmonary exacerbation in cystic fibrosis. $J$ Pediatr 1999; 134: 413-421.

61. Pennington JE. Penetration of antibiotics into respiratory secretions. Rev Infect Dis 1981; 3: 67-73.

62. Bergogne-Berezin E. Pharmacokinetics of antibiotics in cystic fibrosis patients with particular reference to the bronchopulmonary tree. Infection 1987; 15: 288-294.

63. Prandota J. Clinical pharmacology of antibiotics and other drugs in cystic fibrosis. Drugs 1988; 35: 542-578.

64. Touw DJ, Vinks AA, Mouton JW, Horrevorts AM. Pharmacokinetic optimisation of antibacterial treatment in patients with cystic fibrosis. Current practice and suggestions for future directions. Clin Pharmacokinet 1998; 35: 437-459.

65. Baran D, de Vuyst P, Ooms HA. Concentration of tobramycin given by aerosol in the fluid obtained by bronchoalveolar lavage. Respir Med 1990; 84: 203-204.

66. Decre D, Bergogne-Berezin E. Pharmacokinetics of quinolones with special reference to the respiratory tree. J Antimicrob Chemother 1993; 31: 331-343.

67. Valcke Y, Pauwels R, Van der Straeten M. Pharmacokinetics of antibiotics in the lungs. Eur Respir J 1990; 3: 715-722.

68. Vic P, Ategbo S, Turck D, et al. Efficacy, tolerance, and 
pharmacokinetics of once daily tobramycin for Pseudomonas exacerbations in cystic fibrosis. Arch Dis Child 1998; 78: 536-539.

69. Toso C, Williams DM, Noone PG. Inhaled antibiotics in cystic fibrosis: a review. Ann Pharmacother 1996; 30: 840-850.

70. Lietman PS. Pharmacokinetics of antimicrobial drugs in cystic fibrosis; $\beta$-lactam antibiotics. Chest 1988; 94 : S115-S118.

71. Smith MJ, White LO, Bowyer H, Willis J, Hodson ME, Batten JC. Pharmacokinetics and sputum penetration of ciprofloxacin in patients with cystic fibrosis. Antimicrob Agents Chemother 1986; 30: 614-616.

72. Frederiksen B, Koch C, Høiby N. Antibiotic treatment of initial colonization with Pseudomonas aeruginosa postpones chronic infection and prevents deterioration of pulmonary function in cystic fibrosis. Pediatr Pulmonol 1997; 23: 330-335.

73. Conway SP, Pond MN, Watson A, Etherington C, Robey HL, Goldman MH. Intravenous colistin sulphomethate in acute respiratory exacerbations in adult patients with cystic fibrosis. Thorax 1997; 52: 987-993.

74. Ledson MJ, Gallagher MJ, Cowperthwaite C, Convery RP, Walshaw MJ. Four years' experience of intravenous colomycin in an adult cystic fibrosis unit. Eur Respir $J$ 1998; 12: 592-594.

75. Hunt BE, Weber A, Berger A, Ramsey B, Smith AL. Macromolecular mechanisms of sputum inhibition of tobramycin activity. Antimicrob Agents Chemother 1995; 39: $34-39$

76. Levy J, Smith AL, Koup JR, Williams-Warren J, Ramsey B. Disposition of tobramycin in patients with cystic fibrosis: a prospective controlled study. J Pediatr 1984; 105: 117-124.

77. Levy J. Antibiotic activity in sputum. J Pediatr 1986; 108: 841-846.

78. Ramphal R, Lhermitte M, Filliat M, Roussel P. The binding of anti-pseudomonal antibiotics to macromolecules from cystic fibrosis sputum. J Antimicrob Chemother 1988; 22: 483-490.

79. Nickel JC, Ruseska I, Wright JB, Costerton JW. Tobramycin resistance of Pseudomonas aeruginosa cells growing as a biofilm on urinary catheter material. Antimicrob Agents Chemother 1985; 27: 619-624.

80. Cantin AM, Woods DE. Protection by antibiotics against myeloperoxidase-dependent cytotoxicity to lung epithelial cells in vitro. J Clin Invest 1993; 91: 38-45.

81. Dalhoff A, Döring G. Interference of ciprofloxacin with the expression of pathogenicity factors of Pseudomonas aeruginosa. In: Adam D, Hahn H, Opferkuch W, eds. The Influence of Antibiotics on the Host-parasite Relationship II. Berlin, Springer, 1985; pp. 246-255.

82. Grimwood K, To M, Rabin HR, Woods DE. Inhibition of Pseudomonas aeruginosa exoenzyme expression by subinhibitory antibiotic concentrations. Antimicrob Agents Chemother 1989; 33: 41-47.

83. Øgaard AR, Bjøro K, Bukholm G, Berdal BP. Pseudomonas aeruginosa virulence factors: modifications by sub-inhibitory concentrations of carbenicillin or gentamycin. Acta Path Microbiol Immunol Scand [B] 1986; 94: 63-68.

84. Shibl A. Effect of antibiotics on production of enzymes and toxins by microorganisms. Rev Infect Dis 1983; 5: 865-875.

85. Blumer JL, Stern RC, Klinger JD, et al. Ceftazidime therapy in patients with cystic fibrosis and multiply-drugresistant Pseudomonas. Am J Med 1985; 79: 37-46.
86. Christensson BA, Ljungberg B, Eriksson L, Nilsson-Ehle I. Pharmacokinetics of meropenem in patients with cystic fibrosis. Eur JClin Microbiol Infect Dis 1998; 17: 873-876.

87. de Groot R, Smith AL. Antibiotic pharmacokinetics in cystic fibrosis. Differences and clinical significance. Clin Pharmacokinet 1987; 13: 228-253.

88. de Groot R, Hack BD, Weber A, Chaffin D, Ramsey B, Smith AL. Pharmacokinetics of ticarcillin in patients with cystic fibrosis: a controlled prospective study. Clin Pharmacol Ther 1990; 47: 73-78.

89. Bragonier R, Brown NM. The pharmacokinetics and toxicity of once-daily tobramycin therapy in children with cystic fibrosis. J Antimicrob Chemother 1998; 42: 103-106.

90. Mann HJ, Canafax DM, Cipolle RJ, Daniels CE, Zaske DE, Warwick WJ. Increased dosage requirements of tobramycin and gentamicin for treating Pseudomonas pneumonia in patients with cystic fibrosis. Pediatr Pulmonol 1985; 1: 238-243.

91. Prandota J. Drug disposition in cystic fibrosis: progress in understanding pathophysiology and pharmacokinetics. Pediatr Infect Dis 1987; 6: 1111-1126.

92. Spino M. Pharmacokinetics of drugs in cystic fibrosis. Clin Rev Allergy 1991; 9: 169-210.

93. Horrevorts AM, de Witte J, Degener JE, et al. Tobramycin in patients with cystic fibrosis. Adjustment in dosing interval for effective treatment. Chest 1987; 92 : 844-848.

94. Davis RL, Koup JR, Williams-Warren J, et al. Pharmacokinetics of ciprofloxacin in cystic fibrosis. Antimicrob Agents Chemother 1987; 31: 915-919.

95. Reed MD, Stern RC, Myers CM, Yamashita TS, Blumer JL. Lack of unique ciprofloxacin pharrnacokinetic characteristics in patients with cystic fibrosis. $J$ Clin Pharmacol 1988; 28: 691-699.

96. Stutman HR, Shalit I, Marks MI, Greenwood R, Chartrand SA, Hilman BC. Pharmacokinetics of two dosage regimens of ciprofloxacin during a two-week therapeutic trial in patients with cystic fibrosis. Am J Med 1987; 82: 142-145.

97. Reed MD, Stern RC, O'Brien CA, Crenshaw DA, Blumer JL. Randomized doubleblind evaluation of ceftazidime dose ranging in hospitalized patients with cystic fibrosis. Antimicrob Agents Chemother 1987; 31: 698-702.

98. Ciofu O, Jensen T, Pressler T, Krogh Johansen H, Koch C, Høiby N. Meropenem in cystic fibrosis patients infected with resistant Pseudomonas aeruginosa or Burholderia cepacia with hypersensitivity to $\beta$-lactam antibiotics. Clin Microbiol Infect 1996; 2: 91-98.

99. Mendelman PM, Smith AL, Levy J, Weber A, Ramsey B, Davis RL. Aminoglycoside penetration, inactivation, and efficacy in cystic fibrosis sputum. Am Rev Respir Dis 1985; 132: 761-765.

100. Product information: tobramycin. Indianapolis, Eli Lilly and Company, 1992.

101. den Hollander JG, Mouton JW, van Goor MP, Vleggaar FP, Verbrugh HA. Alteration of postantibiotic effect during one dosing interval of tobramycin, simulated in an in vitro pharmacokinetic model. Antimicrob Agents Chemother 1996; 4: 784-786.

102. Powell SH, Thompson WL, Luthe MA, Stern RC, Grossinklaus DA, Blockshaw DD. Once-daily vs. continuous aminoglycoside dosing: efficacy and toxicity in animal and clinical studies of gentamicin, netilmicin, and tobramycin. J Infect Dis 1983; 147: 918-932.

103. Wood PJ, Ioannides-Demos LL, Li SC, et al. Minimisation of aminoglycoside toxicity in patients with cystic fibrosis. Thorax 1996; 51: 369-373. 
104. Reed MD, Stern RC, Myers CM, Klinger JD, Yamashita TS, Blumer JL. Therapeutic evaluation of piperacillin for acute pulmonary exacerbations in cystic fibrosis. Pediatr Pulmonol 1987; 3: 101-109.

105. Stead RJ, Kennedy HG, Hodson ME, Batten JC. Adverse reactions to piperacillin in adults with cystic fibrosis. Thorax 1985; 40: 184-186.

106. Stern RC. Denmark to the rescue. Pediatr Pulmonol 1996; 21: 151-152.

107. Ghani M, Soothill JS. Ceftazidime, gentamicin, and rifampicin, in combination, kill biofilms of mucoid Pseudomonas aeruginosa. Can J Microbiol 1997; 43: 999-1004.

108. Jaffe A, Francis J, Rosenthal M, Bush A. Long-term azithromycin may improve lung function in children with cystic fibrosis. Lancet 1998; 351: 420.

109. Kobayashi H. Biofilm disease: its clinical manifestation and therapeutic possibilities of macrolides. $\mathrm{Am} \mathrm{J} \mathrm{Med}$ 1995; 99: 26S-30S.

110. British Thoracic Society Research Committee. Ceftazidime compared with gentamicin and carbenicillin in patients with cystic fibrosis, pulmonary pseudomonas infection, and an exacerbation of respiratory symptoms. Thorax 1985; 40: 358-363.

111. Permin H, Koch C, Høiby N, Christensen HO, Moller AF, Moller S. Ceftazidime treatment of chronic Pseudomonas aeruginosa respiratory tract infection in cystic fibrosis. J Antimicrob Chemother 1983; 12: 313-323.

112. Huang NN, Hiller EJ, Macri CM, Capitanio M, Cundy KR. Carbenicillin in patients with cystic fibrosis: clinical pharmacology and therapeutic evaluation. J Pediatr 1971; 78: 338-345.

113. Schaad UB, Wedgewod-Krucko J, Suter S, Kraemer R. Efficacy of inhaled amikacin as adjunct to intravenous combination therapy (ceftazidime and amikacin) in cystic fibrosis. J Pediatr 1987; 111: 599-605.

114. Stephens D, Garey N, Isles A, Levison H, Gold R. Efficacy of inhaled tobramycin in the treatment of pulmonary exacerbations in children with cystic fibrosis. Pediatr Infect Dis 1983; 2: 209-211.

115. Weber A, Morlin G, Cohen M, Williams-Warren J, Ramsey B, Smith AL. Effect of nebulizer type and antibiotic concentration on device performance. Pediatr Pulmonol 1997; 23: 249-260.

116. Abramowsky CR, Swinehart GL. The nephropathy of cystic fibrosis: a human model of chronic nephrotoxicity. Hum Pathol 1982; 3: 934-939.

117. Katbamna B, Homnick DN, Marks JH. Contralateral suppression of distortion product otoacoustic emissions in children with cystic fibrosis: effects of tobramycin. $J \mathrm{Am}$ Acad Audiol 1998; 9: 172-178.

118. Sone M, Schachern PA, Paparella MM. Loss of spiral ganglion cells as primary manifestation of aminoglycoside ototoxicity. Hear Res 1998; 115: 217-223.

119. Green CG, Doershuk CF, Stern RC. Symptomatic hypomagnesaemia in cystic fibrosis. J Pediatr 1985; 107: 425428.

120. Smith DL, Stableforth DL, Geddes AM. Evaluation of a once-daily netilmicin regimen in the treatment of cystic fibrosis. J Antimicrob Chemother 1994; 33: 191-193.

121. Mulheran M, Degg C, Burr SA, et al. The occurrence and risk estimate of ototoxicity in CF patients receiving frequent aminoglycoside therapy. Pediatr Pulmonol 1999; (Suppl. 19): 263.

122. Pedersen SS, Jensen T, Osterhammel D, Osterhammel P. Cumulative and acute toxicity of repeated high-dose tobramycin treatment in cystic fibrosis. Antimicrob Agents Chemother 1987; 31: 594-599.

123. Byrne S, Maddison J, Connor P, et al. Clinical evaluation of meropenem versus ceftazidime for the treatment of Pseudomonas spp. infections in cystic fibrosis patients. J Antimicrob Chemother 1995; 36: 135-143.

124. Jensen T, Pedersen SS, Høiby N, Koch C. Safety of aztreonam in patients with cystic fibrosis and allergy to $\beta$ lactam antibiotics. Rev Infect Dis 1991; 13: S594-S597.

125. Koch C, Hjelt K, Pedersen SS, et al. Retrospective clinical study of hypersensitivity reactions to aztreonam and six other $\beta$-lactam antibiotics in cystic fibrosis patients receiving multiple treatment courses. Rev Infect Dis 1991; 13: S608-S611.

126. Moss RB. Drug allergy in cystic fibrosis. Clin Rev Allergy 1991; 9: 211-229.

127. Pleasants RA, Walker TR, Samuelson WM. Allergic reactions to parenteral beta-lactam antibiotics in patients with cystic fibrosis. Chest 1994; 106: 1124-1128.

128. Pedersen SS, Pressler T, Jensen T, et al. Combined imipenem/cilastatin and tobramycin therapy of multiresistant Pseudomonas aeruginosa in cystic fibrosis. $J$ Antimicrob Chemother 1987; 19: 101-107.

129. Battersby NC, Patel L, David TJ. Increasing dose regimen in children with reactions to ceftazidime. Clin Exp Allergy 1995; 25: 1211-1217.

130. Hodson ME, Roberts CM, Butland RJ, Smith MJ, Batten JC. Oral ciprofloxacin compared with conventional intravenous treatment for Pseudomonas aeruginosa infection in adults with cystic fibrosis. Lancet 1987; 1: 235-237.

131. Klinger JD, Aronoff SC. In vitro activity of ciprofloxacin and other antibacterial agents against Pseudomonas aeruginosa and Pseudomonas cepacia from cystic fibrosis patients. J Antimicrob Chemother 1985; 15: 679-684.

132. Shalit I, Stutman HR, Marks MI, Chartrand SA, Hilman BC. Randomized study of two dosage regimens of ciprofloxacin for treating chronic bronchopulmonary infection in patients with cystic fibrosis. Am J Med 1987; 82: 189-195.

133. Church DA, Kanga JF, Kuhn RJ, et al. Sequential ciprofloxacin therapy in pediatric cystic fibrosis: comparative study $v s$. ceftazidime/tobramycin in the treatment of acute pulmonary exacerbations. The Cystic Fibrosis Study Group. Pediatr Infect Dis J 1997; 16: 97-105.

134. Schaad UB, Wedgwood-Krucko J, Guenin K, Buehlmann U, Kraemer R. Antipseudomonal therapy in cystic fibrosis: aztreonam and amikacin versus ceftazidime and amikacin administered intravenously followed by oral ciprofloxacin. Eur J Clin Microbiol Infect Dis 1989; 8: 858-865.

135. Jensen T, Pedersen SS, Høiby N, Koch C. Efficacy of oral fluoroquinolones versus conventional intravenous antipseudomonal chemotherapy in treatment of cystic fibrosis. Eur J Clin Microbiol 1987; 6: 618-622.

136. Adam D. Use of quinolones in pediatric patients. Rev Infect Dis 1989; 11: S1113-S1116.

137. Richard DA, Nousia-Arvanitakis S, Sollich V, Hampel BJ, Sommerauer B, Schaad UB. Oral ciprofloxacin vs. intravenous ceftazidime plus tobramycin in pediatric cystic fibrosis patients: comparison of antipseudomonas efficacy and assessment of safety with ultrasonography and magnetic resonance imaging. Cystic Fibrosis Study Group. Pediatr Infect Dis $J$ 1997; 16: 572-578.

138. Burkhardt JE, Walterspiel JN, Schaad UB. Quinolone arthropathy in animals versus children. Clin Infect Dis 1997; 25: 1196-1204.

139. Schaad UB, Abdus Salam M, Aujard Y, et al. Use of 
fluoroquinolones in pediatrics: consensus report of an International Society of Chemotherapy commission. Pediatr Infect Dis J 1995; 14: 1-9.

140. Schaad UB. Pediatric use of quinolones. Pediatr Infect Dis $J$ 1999; 18: 469-470.

141. Le Conte P, Potel G, Peltier P, et al. Lung distribution and pharmacokinetics of aerosolized tobramycin. Am Rev Respir Dis 1993; 147: 1279-1282.

142. Touw DJ, Brimicombe RW, Hodson ME, Heijerman HG, Bakker W. Inhalation of antibiotics in cystic fibrosis. Eur Respir J 1995; 8: 1594-1604.

143. Hodson ME, Penketh ARL, Batten JC. Aerosol carbenicillin and gentamicin treatment of Pseudomonas aeruginosa in cystic fibrosis: current status of the hostbacterium interaction. Lancet 1981; 2: 1137-1139.

144. Kun P, Landau LI, Phelan PD. Nebulized gentamicin in children and adolescents with cystic fibrosis. Aust Paediatr J 1984; 20: 43-45.

145. Littlewood JM, Miller MG, Ghoneim AT, Ramsden CH. Nebulised colomycin for early Pseudomonas colonisation in cystic fibrosis. Lancet 1985; 1: 865.

146. Valerius NH, Koch C, Høiby N. Prevention of chronic Pseudomonas aeruginosa colonization in cystic fibrosis by early treatment. Lancet 1991; 338: 725-672.

147. Mukhopadhyay S, Singh M, Cater JI, Ogston S, Franklin M, Olver RE. Nebulised antipseudomonal antibiotic therapy in cystic fibrosis: a meta-analysis of benefits and risks. Thorax 1996; 51: 364-368.

148. Wiesemann HG, Steinkamp G, Ratjen F, et al. Placebo controlled, double blind, randomized study of aerosolized tobramycin for early treatment of Pseudomonas aeruginosa colonization in patients with cystic fibrosis. Pediatr Pulmonol 1998; 25: 88-92.

149. Campbell PW III, Saiman L. Use of aerosolized antibiotics in patients with cystic fibrosis. Chest 1999; 116 : $775-788$.

150. Conway SP. Evidence for using nebulised antibiotics in cystic fibrosis. Arch Dis Child 1999; 80: 307-309.

151. Mukhopadhyay S, Baer S, Blanshard J, Coleman M, Carswell F. Assessment of potential ototoxicity following high-dose nebulized tobramycin in patients with cystic fibrosis. J Antimicrob Chemother 1993; 31: 429-436.

152. Touw DJ, Jacobs FA, Brimicombe RW, Heijerman HG, Bakker W, Briemer DD. Pharmacokinetics of aerosolized tobramycin in adult patients with cystic fibrosis. Antimicrob Agents Chemother 1997; 41: 184-187.

153. Chua HL, Collis GG, Le Souef PN. Bronchial response to nebulized antibiotics in children with cystic fibrosis. Eur Respir J 1990; 3: 1114-1116.

154. Maddison J, Dodd M, Webb AK. Nebulized colistin causes chest tightness in adults with cystic fibrosis. Respir Med 1994; 88: 145-147.

155. Nikolaizik WH, Jenni-Galovic V, Schoni MH. Bronchial constriction after nebulized tobramycin preparations and saline in patients with cystic fibrosis. Eur J Pediatr 1996; 155: 608-611.

156. Dodd ME, Abbott J, Maddison J, Moorcroft AJ, Webb AK. Effect of tonicity of nebulised colistin on chest tightness and pulmonary function in adults with cystic fibrosis. Thorax 1997; 52: 656-658.

157. Eisenberg J, Pepe M, Williams-Warren $\mathrm{J}$, et al. A comparison of peak sputum tobramycin concentration in patients with cystic fibrosis using jet and ultrasonic nebulizer systems. Chest 1997; 111: 955-962.

158. Goldman JM, Bayston SM, O'Connor S, Meigh RE. Inhaled micronised gentamicin powder: a new delivery system. Thorax 1990; 45: 939-940.
159. Faurisson F, Dessanges JF, Grimfeld A, et al. Nebulizer performance: AFLM study. Association Francaise de Lutte contre la Mucoviscidose. Respir 1995; 62: 13-18.

160. Newman SP, Clarke SW. Therapeutic aerosols 1. Physical and practical considerations. Thorax 1983; 38: 881-886.

161. Coates AL, MacNeish CF, Meisner D, et al. The choice of jet nebulizer, nebulizing flow, and addition of albuterol affects the output of tobramycin aerosols. Chest 1997; 111: 1206-1212.

162. Hess D, Fisher D, Williams P, Pooler S, Kacmarek RM. Medication nebulizer performance. Effects of diluent volume, nebulizer flow, and nebulizer brand. Chest 1996; 110: 498-505.

163. Ilowite JS, Gorvoy JD, Smaldone GC. Quantitative deposition of aerosolized gentamicin in cystic fibrosis. Am Rev Respir Dis 1987; 136: 1445-1449.

164. Ilowite JS, Smaldone GC, Perry RN, Bennett WD, Foster WM. Relationship between tracheobronchial particle clearance rates and sites of initial deposition in man. Arch Environ Health 1989; 44: 267-273.

165. Mukhopadhyay S, Staddon GE, Eastman C, Palmer M, Davies ER, Carswell F. The quantitative distribution of nebulised antibiotic in the lung in cystic fibrosis. Respir Med 1994; 88: 203-211.

166. Newman SP, Pellow PG, Clay MM, Clarke SW. Evaluation of jet nebulisers for use with gentamicin solution. Thorax 1985; 40: 671-676.

167. Newman SP, Pellow PGD, Clarke SW. Droplet size distribution of nebulised aerosols for inhalation therapy. Clin Phys Physiol Meas 1986; 7: 139-146.

168. Newman SP, Pellow PG, Clarke SW. Choice of nebulisers and compressors for delivery of carbenicillin aerosol. Eur J Respir Dis 1986; 69: 160-168.

169. Newman SP, Woodman G, Clarke SW. Deposition of carbenicillin aerosols in cystic fibrosis: effects of nebuliser system and breathing pattern. Thorax 1988; 43: 318-322.

170. Terzano C, Mannino F. Tobramycin aerosol: could the delivery system influence the particle size and deposition in the lower airways? Recenti Prog Med 1998; 89: 245249.

171. Weber A, Smith A, Williams-Warren J, Ramsey B, Covert DS. Nebulizer delivery of tobramycin to the lower respiratory tract. Pediatr Pulmonol 1994; 17: 331-339.

172. Alvine GF, Rodgers P, Fitzsimmons KM, Ahrens RC. Disposable jet nebulizers: how reliable are they? Chest 1992; 101: 316-319.

173. MacLusky I, Levison H, Gold R, McLaughlin FJ. Inhaled antibiotics in cystic fibrosis: Is there a therapeutic effect? $J$ Pediatr 1986; 108: 861-865.

174. Laube BL, Links JM, LaFrance ND, Wagner HN Jr, Rosenstein BJ. Homogeneity of bronchopulmonary distribution of 99Tc aerosol in normal subjects and in cystic fibrosis patients. Chest 1989; 95: 822-830.

175. Laube BL, Chang DY, Blask AN, Rosenstein BJ. Radioaerosol assessment of lung inprovement in cystic fibrosis patients treated for acute pulmonary exacerbations. Chest 1992; 101: 1302-1308.

176. Kuni CC, Regelmann WE, duCret RP, Boudreau RJ, Budd JR. Aerosol scintigraphy in the assessment of therapy for cystic fibrosis. Clin Nucl Med 1992; 17: 90-93.

177. Heaf DP, Webb GJ, Matthew DJ. In vitro assessment of combined antibiotic and mucolytic treatment for Pseudomonas aeruginosa infection in cystic fibrosis. Arch Dis Child 1983; 58: 824-826.

178. Wanner A, Rao A. Clinical indications for and effects of blind, mucolytic and antimicrobial aerosols. Am Rev Respir Dis 1980; 122: 79-103. 
179. Roberts DE, Cole P. The carbenicillin potentiating effect of $N$-acetylcysteine in vitro. Eur J Pediatr 1981; 137: 78.

180. Shak S, Capon DJ, Hellniss R, Masters SA, Baker CL. Recombinant human DNAse I reduces the viscosity of cystic fibrosis sputum. Proc Natl Acad Sci USA 1990; 87: 188-192.

181. Alfredsson H, Malmborg AS, Strandvik B. Nacetylcysteine and 2-mercaptoethane sulphonate inhibit anti-pseudomonas activity of antibiotics in vitro. Eur $J$ Respir Dis 1987; 70: 213-217.

182. Standaert TA, Morlin GL, Williams-Warren J, et al. Effects of repetitive use and cleaning techniques of disposable jet nebulizers on aerosol generation. Chest 1998; 114: 577-586.

183. Weaver LT, Green MR, Nicholson K, et al. Prognosis in cystic fibrosis treated with continuous flucloxacillin from the neonatal period. Arch Dis Child 1994; 70: 84-89.

184. Frederiksen B, Koch C, Høiby N. Changing epidemiology of Pseudomonas aeruginosa infection in Danish cystic fibrosis patients (1974-1995). Pediatr Pulmonol 1999; 8: 59-66.

185. Kuzemko JA. Home treatment of pulmonary infection in cystic fibrosis. Chest 1988; 94: 162S-165S.

186. Vinks AA, Brimicombe RW, Heijerman HG, Bakker W. Continuous infusion of ceftazidime in cystic fibrosis patients during home treatment: clinical outcome, microbiology and pharmacokinetics. J Antimicrob Chemother 1997; 40: 125-133.
187. Wolter JM, Bowler SD, Nolan PJ, McCormack JG. Home intravenous therapy in cystic fibrosis: a prospective randomized trial examining clinical, quality of life and cost aspects. Eur Respir J 1997; 10: 896-900.

188. Rosenfeld M, Emerson J, Astley S, et al. Home nebulizer use among patients with cystic fibrosis. J Pediatr 1998; 132: $125-131$.

189. Szaff M, Høiby N, Flensborg EW. Frequent antibiotic therapy improves survival of cystic fibrosis patients with chronic Pseudomonas aeruginosa infection. Acta Paediatr Scand 1983; 72: 651-657.

190. Zach MS. Lung disease in cystic fibrosis-an updated concept. Pediatr Pulmonol 1990; 8: 188-202.

191. Stern RC. Denmark to the rescue. Pediatr Pulmonol 1996; 21: 151-152.

192. Huet F, Nivelon JL. Aerosoltherapie et mucoviscidose: enquete nationale. Rev Pneumol Clin 1997; 53: 91-97.

193. Taylor RF, Hodson ME. Cystie fibrosis: antibiotie preseribing practices in the United Kingdom and Eire. Respir Med 1993; 87: 535-539.

194. Smith AL. Antibiotie therapy in eystie fibrosis: evaluation of elinieal trials. J Pediatr 1986; 108: 866-870.

195. Pattishall EN. Negative elinieal trials in eystic fibrosis research. Pediatrics 1990; 85: 277-281.

196. Ramsey BW, Boat TF. Outcome measures for clinical trials in cystic fibrosis. Summary of a cystic fibrosis foundation consensus conference. J Pediatr 1994; 124: 177-192. 